\title{
Insights into biotic and abiotic modulation of ocean mesopelagic communities
}

Janaina Rigonato ${ }^{1,17^{*} \#}$, Marko Budinich ${ }^{2,3^{*}}$, Alejandro A. Murillo ${ }^{4}$, Manoela C. Brandão ${ }^{5}$, Juan J. Pierella Karlusich ${ }^{6}$, Yawouvi Dodji Soviadan ${ }^{5}$, Ann C. Gregory ${ }^{7}$, Hisashi Endo ${ }^{8}$, Florian Kokoszka $^{6,9}$, Dean Vik ${ }^{7}$, Nicolas Henry ${ }^{2}$, Paul Frémont ${ }^{1}$, Karine Labadie ${ }^{1}$, Ahmed A. Zayed ${ }^{7}$, Céline Dimier $^{2,6,17}$, Marc Picheral ${ }^{5,17}$, Sarah Searson ${ }^{5}$, Julie Poulain ${ }^{1,17}$, Stefanie Kandels ${ }^{4,10}$, Stéphane Pesant ${ }^{11,12}$, Eric Karsenti ${ }^{6,10}$, The Tara Oceans coordinators ${ }^{\S}$, Peer Bork ${ }^{6,13}$, Chris Bowler $^{6,17}$, Samuel Chaffron ${ }^{3,17}$, Colomban de Vargas ${ }^{2,17}$, Damien Eveillard ${ }^{3,17}$, Marion Gehlen $^{14}$, Daniele ludicone ${ }^{9}$, Fabien Lombard ${ }^{5,17}$, Hiroyuki Ogata ${ }^{8}$, Lars Stemmann ${ }^{5,17}$, Matthew B. Sullivan ${ }^{7,15}$, Shinichi Sunagawa ${ }^{4,16}$, Patrick Wincker ${ }^{1,17}$ and Olivier Jaillon ${ }^{1,17 \#}$

1 Génomique Métabolique, Genoscope, Institut de Biologie François Jacob, Commissariat à l'Energie Atomique (CEA), CNRS, Université Evry, Université Paris-Saclay, 91000 Evry, France

2 Sorbonne Université, CNRS, Station Biologique de Roscoff, AD2M, UMR 7144, 29680 Roscoff, France

3 Université de Nantes, CNRS UMR 6004, LS2N, F-44000 Nantes, France

4 Structural and Computational Biology, European Molecular Biology Laboratory, Meyerhofstr. 1, 69117 Heidelberg, Germany

5 Sorbonne Université, CNRS, Laboratoire d'Océanographie de Villefranche (LOV), 06230

Villefranche-sur-Mer, France

6 Institut de Biologie de l'ENS (IBENS), Département de biologie, Ecole normale supérieure, CNRS, INSERM, Université PSL, 75005 Paris, France

7 Department of Microbiology, The Ohio State University, Columbus, OH 43214, USA

8 Bioinformatics Center, Institute for Chemical Research Kyoto University, Gokasho, Uji, Kyoto, 611-0011, Japan

9 Stazione Zoologica Anton Dohrn, Villa Comunale, 80121 Naples, Italy

10 Directors' Research European Molecular Biology Laboratory Meyerhofstr. 169117 Heidelberg Germany

11 MARUM, Center for Marine Environmental Sciences, University of Bremen, Bremen, Germany

12 PANGAEA, Data Publisher for Earth and Environmental Science, University of Bremen, Bremen, Germany

13 Department of Bioinformatics, Biocenter, University of Würzburg, Würzburg, Germany

14 Institut Pierre Simon Laplace, Laboratoire des Sciences du Climat et de l'Environnement, CEA, CNRS, Université Paris-Saclay, 91191 Gif-sur-Yvette cedex, France

15 Department of Civil, Environmental and Geodetic Engineering, The Ohio State University, Columbus $\mathrm{OH} 43214$ USA

16 Department of Biology; Institute of Microbiology and Swiss Institute of Bioinformatics, ETH Zurich; Zurich, 8093; Switzerland

17 Research Federation for the study of Global Ocean Systems Ecology and Evolution, FR2022/Tara Oceans GOSEE, 3 rue Michel-Ange,75016 Paris, France

${ }^{*}$ These authors share the first authorship

\# Corresponding authors: jana_rigonato@protonmail.com (JR); ojaillon@genoscope.cns.fr (OJ)

Running title: Mesopelagic community ecology 


\begin{abstract}
Marine plankton mitigate anthropogenic greenhouse gases, modulate biogeochemical cycles, and provide fishery resources. Plankton is distributed across a stratified ecosystem of sunlit surface waters and a vast, though understudied, mesopelagic 'dark ocean'. In this study, we mapped viruses, prokaryotes, and pico-eukaryotes across 32 globally-distributed cross-depth samples collected during the Tara Oceans Expedition, and assessed their ecologies. Based on depth and $\mathrm{O}_{2}$ measurements, we divided the marine habitat into epipelagic, oxic mesopelagic, and oxygen minimum zone (OMZ) eco-regions. We identified specific communities associated with each marine habitat, and pinpoint environmental drivers of dark ocean communities. Our results indicate that water masses primarily control mesopelagic community composition. Through co-occurrence network inference and analysis, we identified signature communities strongly associated with OMZ eco-regions. Mesopelagic communities appear to be constrained by a combination of factors compared to epipelagic communities. Thus, variations in a given abiotic factor may cause different responses in sunlit and dark ocean communities. This study expands our knowledge about the ecology of planktonic organisms inhabiting the mesopelagic zone.
\end{abstract}

Keywords: mesopelagic community, metabarcoding, plankton, pan-oceanic expedition, oxygen minimum zone 


\section{Introduction}

Below the ocean's sunlit layer lies the mesopelagic zone that occupies around $20 \%$ of the global ocean volume [1]. The mesopelagic zone is biologically defined as starting where photosynthesis no longer occurs ( $<1 \%$ irradiance around $200 \mathrm{~m}$ depth), down to its lower boundary where there is no detectable sunlight (around $1000 \mathrm{~m}$ depth) [2]. This twilight ecosystem cannot rely on photoautotrophy, but sustains its energetic requirements by the combination of heterotrophic, chemoautotrophic, and chemo-mixotrophic metabolisms, together with physicochemical processes. Among the latter, the fraction of upper ocean productivity that escapes epipelagic recycling and sinks by gravity or is delivered by the daily migration of zooplankton constitutes an essential energy source in deep waters and is a vector for attached organisms [3].

The biodiversity and biomass in mesopelagic communities have been underestimated in the past $[2,4]$, and previous work showed these communities hold an enormous unexploited biological resource $[5,6,1]$. Mesopelagic organisms are considered to be a vast source of fat and protein, potentially becoming the primary source of global bioeconomy [7]. So far, efforts have been made to increase knowledge of mesopelagic mega/macrofauna by studying the abundance and diversity of nekton. These efforts are of great importance, given the rapid increase in the exploitation of this zone by nutraceutical and fisheries industries [6]. However, less attention has been devoted to the mesopelagic community's microscopic fraction, despite the pivotal role of the marine microbiome in biogeochemical cycles. The marine microbiome makes crucial links in the food web between primary production and dark ocean specialized consumers. Previous reports have shown stratification of planktonic communities with depth. In this regard, the mesopelagic zone displays a distinct assemblage of dsDNA viruses [8], giant viruses [9], prokaryotes [10, 11], and eukaryotes [12]. However, unlike the epipelagic layer, mesopelagic plankton diversity does not show the latitudinal diversity gradient trends from pole-to-pole, peaking at lower latitudes [13].

Among the studies conducted in mesopelagic zones, we highlight the efforts to explore regions of extreme conditions, such as oxygen minimum zones (OMZs). These zones are formed by 
relatively old slowly upwelling waters, often lying below highly productive surface zones [14], and are currently increasing in volume in the oceans [15]. OMZ prokaryotic communities are well documented and predominated by taxa such as Nitrospira, Marinimicrobia, and anammox bacteria from the phylum Planctomycetes, while Thaumarchaeota abundance is frequently lower in these zones $[16,17,18,19,20]$. In contrast, knowledge of eukaryotic diversity in OMZs is still rudimentary, but a prevalence of specific taxa such as Ciliophora, Dinoflagellata, MALV, and Acantharia has been reported, together with a higher metabolic activity of these taxa [21, 22, 23]. Understanding plankton community structure and dynamics is fundamental to anticipate the impacts of global warming and acidification in these regions.

114 The last decades have seen a significant increase in large-scale oceanic surveys [24, 25, 26]. However, most mesopelagic community studies have been limited to geographically or 116 ecologically fragmented regions, or to specific taxonomic groups, mainly because of the 117 inherent difficulties of accessing this zone on a global scale [5]. Hence, these studies have 118 given us a limited picture of community composition. Moreover, the factors influencing 119 community structure, presumably a combination of biotic and abiotic factors [27, 28], have 120 been little explored in the mesopelagic zone.

121 The present study takes advantage of the Tara Oceans large-scale survey conducted in 122 different water layers using a systematic sampling protocol, spanning viruses to small 123 eukaryote size fractions, to investigate the mesopelagic biome [29]. We capitalized on genomic 124 data together with extensive contextual data and ocean geography to explore the particularities 125 of mesopelagic communities compared to communities found in the euphotic zone. We also 126 investigated potential water deoxygenation effects on these communities by comparing $\mathrm{OMZ}$ 127 communities with those from well-oxygenated waters. This work expands our knowledge of 128 the web of relationships underpinning mesopelagic plankton ecosystems on a broad 129 geographic scale.

\section{Materials and Methods}


133 The environmental and biological data were obtained during the Tara Oceans expedition

134 (2009-2012) in 32 oceanographic stations located in the Indian Ocean (IO - 037, 038, 039),

135 Pacific Ocean (PO - 097, 098, 100, 102, 106, 109, 110, 111, 112, 122, 131, 132, 133, 135,

136 137, 138), South Atlantic Ocean (SAO - 068, 070, 072, 076, 078) and North Atlantic Ocean

137 (NAO - 142, 143, 144, 145, 146, 148, 149, 152) comprising tropical and subtropical regions

138 (Figure 1). Physico-chemical environmental data were obtained along a vertical profile at each

139 station. Temperature, salinity, and oxygen were measured using a CTD-rosette system with a

140 coupled dissolved oxygen sensor. Chlorophyll-a concentrations were measured using high-

141 performance liquid chromatography. Nutrient concentrations were determined using

142 segmented flow analysis. Metadata are available at PANGAEA [30, 31, 32, 33, 34, 35] -

143 (https://doi.pangaea.de/10.1594/PANGAEA.875582).

144 The vertical distribution of marine particles was investigated with an Underwater Vision Profiler

145 (UVP, [36, 37]) mounted on the CTD-Rosette. The UVP acquires images in a coherent water

146 volume $(1 \mathrm{~L})$ delimited by a light sheet issued from red light-emitting diodes. Automatic

147 identification of objects was made using Ecotaxa, based on a learning set of visually identified,

148 manually classified objects and associated features. Images were classified to distinguish

149 mesozooplankton from non-living objects and artifacts (e.g., detritic particles, fibers, and out-

150 of-focus objects).

151 Water vertical profiles of temperature and salinity generated from the CTD were used to identify

152 the water masses by plotting a temperature $\mathrm{x}$ salinity (T/S) diagram using the Ocean Data View

153 V 5.0 (ODV) software package [38].

154 Three different water layers were sampled: surface (SRF, 3-7 m), deep chlorophyll maximum

155 (DCM - depth identified according to the peak of chlorophyll-a fluorescence obtained in situ),

156 and mesopelagic (ranging from 200-1000 m) [39]. The planktonic community was sampled by

157 partitioning the seawater by filtering each sampled depth with different filter sizes [34]. Among

158 the mesopelagic zones, 13 of them were identified as deficient in oxygen and classified as 
oxygen minimum zone (OMZ, stations IO - 037, 038, 039 / PO - 100, 102, 106, 109, 110, 111, $133,135,137,138)$. The $\mathrm{OMZ}$ were categorized as suboxic: $<10 \mu \mathrm{M} \mathrm{O} / \mathrm{kg}$ seawater and anoxic: $(<0.003 \mu \mathrm{M} / \mathrm{kg}$ seawater or undetectable with most sensitive techniques, e.g., STOX sensors) [Units of $\mathrm{O}_{2}$ concentration: $\left.1 \mathrm{~mL} \cdot \mathrm{L}^{-1}=1.43 \mathrm{mg} . \mathrm{L}^{-1}=44.64 \mu \mathrm{M}\right]$ [22].

163 Our dataset comprises different organismal size-fractions from viruses (two dsDNA-virus

164 families Podoviridae and Myoviridae - hereafter named as phages and NCDLV giant viruses -

165 hereafter named as giruses) to pico-eukaryotes. Phage libraries were constructed from seawater samples filtered at $0.22 \mu \mathrm{m}$, concentrated using iron chloride flocculation, and treated with deoxyribonuclease (DNase). Girus polB and prokaryotic 16S rDNA sequences were extracted from plankton metagenomes sequenced from $0.22-1.6$ or $0.22-3 \mu \mathrm{m}$ filters, and the pico-eukaryote dataset was obtained by V9-18S rDNA marker amplification from 0.8-3 or 0.8-

$1705 \mu \mathrm{m}$ filters. Details of sample preparation and sequencing procedures are described in Alberti 171 et al. [40].

172 Phage relative abundance was accessed through the search for the marker genes gp23 173 (Myoviridae) and polA (Podoviridae) in the protein collection GOV2.0 derived from metagenomic sequencing described in Gregory et al. [8]. The girus abundance profile was 175 obtained from polB marker gene gathered from the OM-RGC.v2 catalog [11] as described in 176 Endo et al. [9]. The Prokaryote 16S rDNA marker derived from the metagenome assembly, 177 named 16S Mitag, is described in Sunagawa et al. [10]. Sequences matching "Eukaryota", 178 "chloroplasts", and "mitochondria" were removed from the final table. Clustering and annotation 179 of pico-eukaryote V9-18S rDNA amplicons are described in de Vargas et al. [41], and functional annotation of taxonomically assigned V9-18S rDNA metabarcodes was improved afterward; in

181 this case, we conserved in the final data only sequences assigned to the "Eukaryota" domain.

182 We concatenated SRF and DCM samples for each taxonomic group to obtain an epipelagic 183 dataset (EPI). Counts of OTUs shared in SRF and DCM samples were summed. OTU 184 abundance was normalized by the total counts for each taxonomic group within each sample. 


\section{Epipelagic and Mesopelagic Community and Environmental differences}

We applied an NMDS analysis based on the Bray-Curtis dissimilarity matrix on relative abundances using the 'metaNMDS' function from the vegan $R$ package [42] to confirm community differences between epipelagic and mesopelagic layers. Homogeneity of the sampled environmental parameters was checked using the 'betadisper' function (Homogeneity of multivariate dispersions in the vegan package). The analysis was conducted using the Euclidean distance matrix of the environmental variables using the depths (epipelagic, mesopelagic) as group factor. A permutation test statistically confirmed the results.

\section{Ecological model selection}

197 We used the Species Abundance (SAD) and Rank Abundance Distribution curves (RAD: log 198 abundances vs. rank order) to fit some of the most popular ecological models assessing how 199 communities are assembled [43,44]. Niche/deterministic models presume that the community 200 is under selection due to biotic and abiotic interactions, while neutral/stochastic models assume that random processes structure the community such as drift, migration, birth, and death $[45,46]$. SAD is essential for describing and understanding community assemblage and

203 its management [44]. Further, by showing logarithmic species abundance against a rank order, 204 RAD is commonly used to investigate a community's structure from observations made at one point in space and time $[43,44]$. All the abundance distributions were fitted using 'fitsad' (sads R package - [47]), and 'radfit' (vegan) functions using maximum likelihood estimation. A set of candidate models was selected a priori to be tested by SAD: Log-series, Poisson-lognormal, Broken Stick, Power Law, and the neutral ecological model Zero-sum multinomial distribution.

209 The neutral ecological model describes the SAD of a sample taken from a neutral 210 metacommunity under random drift. The models selected to be tested by RAD were niche pre211 emption models (geometric series or Motomura model), lognormal, Zipf, and Zipf-Mandelbrot, 
and the null model that infers that the individuals are randomly distributed among observed species. For a complete description of each model see Magurran and McGill [48]. The Akaike's Information Criterion (AIC) was used to evaluate the fitted model's quality based on log-likelihood penalized by the number of estimated parameters. AIC estimates the loss of information if the model is assumed for a given dataset. In this manner, models with lower AIC

217 values are selected as better fit conditions [49]. The AIC values produced for each model were 218 compared using the delta AIC $\left(\Delta_{i}\right)$. A $\Delta_{i}$ value $<2$ indicates equally likely models, values $3<\Delta_{i}$ $<9$ indicate less likely models, and $\Delta_{i}>10$ for no likely models [49].

\section{Ecological inferences and statistics}

222 Ecological patterns were inferred using environmental variables to constrain the variation observed in biological data for planktonic samples using Canonical Correspondence Analysis

224 (CCA) in the vegan $\mathrm{R}$ package. A set of physico-chemical variables for the discrete depths were selected for the ecological inferences, such as nitrate $\left(\mathrm{NO}_{3}^{-}\right)$, oxygen, temperature, salinity, density, and particles using particle flux UVP data. In order to avoid collinearity among

227 factors, the selected variables were checked for variance inflation factor using the vif.cca

228 function and tested for significance by 'anova' implemented in vegan with 999 permutations. 229 Each variable effect significance was tested individually using all the others as covariables 230 (independently from their order in the model) by applying the option 'margin' to the 'anova' 231 function in vegan.

232 Permutational multivariate analysis of variance (PERMANOVA) was performed with the 233 function 'adonis' in vegan to determine the relationship between mesopelagic community 234 composition and predefined water masses based on 999 permutations.

\section{Organism Eco-region classification}

237 In order to detect organisms specific to epipelagic (EPI), oxic mesopelagic (Oxic MES), and $238 \mathrm{OMZ}$ eco-regions, only data containing both epipelagic and mesopelagic information were 
considered: in total, 25 stations for giruses, prokaryotes, and pico-eukaryotes, and 13 for phages. First, we discarded OTUs with fewer than 100 reads to remove biases due to rare species' presence, and then recalculated the relative abundances for each dataset. Next, we ran a Kruskal-Wallis test ('kruskal.test' from stats R package [50]) to detect differential OTU relative abundances between eco-regions, followed by a Bonferroni correction to avoid Type I error. Organisms with a p-value $<0.05$, indicating a difference within groups, were subject to a post-hoc Dunn test ('dunn.test' from dunn.test R package [51]) to identify preferential Ecoregions for each OTU. From these results, OTUs statistically equally abundant in all Ecoregions or non-significant Kruskal-Wallis tests were assigned to the "ubiquitous" group. In contrast, those with significant $p$-values were classified as EPI, Oxic MES, or OMZ if only the corresponding Eco-region was elected according to the Dunn test. Organisms with no significant differences between Oxic MES and OMZ were assigned to Core MES.

\section{Co-occurrence Network}

For investigation of associations between organisms across Eco-regions, a co-occurrence network was inferred. In this analysis, phage samples were not included due to the lower number of stations sampled. Therefore, samples for giruses, prokaryotes and pico-eukaryotes from stations $038,039,068,070,072,076,078,098,100,102,109,110,111,112,122,132$, $133,137,138,142,145,146,148,149$ and 152 were retained. OTUs with a relative abundance

$258<10^{-4}$ and counting fewer than 5 observations were discarded. Next, each sample was normalized by applying a centered-log-ratio (CLR) transformation. Network inferences were performed using Flashweave version 0.18 developed in Julia version 1.2 [52], using the sensitive and heterogeneous mode.

We analyzed this global co-occurrence network by delineating communities (or modules) using

263 the Clauset-Newman-Moore algorithm [53]. These modules are subsets of OTUs, obtained by 264 maximizing the co-occurrences within the module and minimizing connections between them.

265 Next, we investigated modules enriched in OTUs from specific Eco-regions using Fisher's exact test using the "fisher.test" function from the stats R package. 


\section{Results and Discussion}

Leveraging the resources produced by the Tara Oceans project, we deciphered differences

on the role of environmental variables such as temperature, oxygen, salinity, $\mathrm{NO}_{3}^{-}$, chlorophyll-

a, and particle flux (see Methods). As previously reported, we observed a stratification by depth of the epipelagic and the mesopelagic communities (i.e., phages, giruses, prokaryotes, and pico-eukaryotes) (Supplementary Figure 1). Consequently, we investigated differences among epipelagic and mesopelagic sampling sites based on Euclidean distance of physicochemical characteristics from each site. We observed a high dissimilarity gradient among sites for both layers (Supplementary Figure 2a, b). Mesopelagic samples were spread in the plot, with most of the points placed distant from the group centroid (located in the center of the cloud of points identified for each group) (Supplementary Figure 2a). In contrast, epipelagic points displayed a large variance due to a few samples positioned apart from the main cluster (Supplementary

282 Figure 2a). These results probably underlie the heterogeneity of environmental conditions encountered in both sampled layers, and this environmental variation may be an important factor that can directly influence community composition.

Community composition variations can also be shaped by four main eco-evolutionary processes: selection, dispersal, drift, and speciation [54]. Mathematical models based on these processes and applied to species abundance (SAD) and rank abundance (RAD) distributions are historically used to infer the ecological or evolutionary mechanisms that structure a given community [55]. Here, we addressed these biological processes to infer the abundance distributions as observed in such natural communities $[56,57]$ in the most diverse environments (terrestrial and aquatic) [45, 46, 43]. We used both SAD and RAD as evidence 292 of ecological processes related to variations in plankton community composition. When applied 293 at the local scale, we excluded random/neutral evolutive effects because all epipelagic and 
mesopelagic communities fit the niche/deterministic ecological models. In fact, in all cases, we

found a $\Delta_{\mathrm{i}}$ value $<2$ for both methods evaluated, which allows us to select one best-fitting model without a subjective judgment (Supplementary Material Table 1 and 2) [49]. In these cases, the community assemblages are mediated by a combination of environmental conditions, interspecies interactions (competition, predation, or mutualisms), and species traits (for instance, phototrophy, parasitism). Specifically, $93 \%$ and $65 \%$ of epipelagic and mesopelagic samples better fit the Lognormal model (Poisson Lognormal SAD [58] and Lognormal RAD [59]), respectively). These results suggest that EPI and MESO plankton populations are affected by the combination of many independent variables, including competitive biotic interactions and abiotic factors [43]. According to this model, the community has a broad and elementary form of organization [57]. Ser-Giacomi et al. [60] stated that the eukaryotic rarebiosphere (non-dominant OTU's) composed of "transient" or occasional taxa in the ocean sunlit layer are mainly governed by dispersal/neutral events. In contrast, and in the case of our findings, the dominant fraction of the assemblage follows idiosyncratic environmental conditions.

Next, to quantify how much of the differences in the assemblages' variance can be explained by environmental conditions, we employed canonical correspondence analysis (CCA) using

311 the environmental variables measured at discrete depths as constraint variables. The results 312 showed that the environment explains only a small fraction of community variance for both 313 layers (32\% on average) (Figure 2 ). The phage assemblage was the exception, for which about $31455 \%$ of the epipelagic variation and $65 \%$ of the mesopelagic variation could be explained by 315 the variables investigated (Figure 2). We tested the variance explained by single explanatory variables individually. In contrast with epipelagic communities mainly governed by temperature 317 and oxygen, as observed here and elsewhere $[10,61,8,13,12,62]$, we could not identify a 318 single environmental predictor structuring entire mesopelagic assemblages. However, a few 319 different variables appeared to be significant for each group (Table 1, complete analysis in 320 Supplementary Material Table 3). Notably, our analysis identified oxygen as the main 
321 mesopelagic driver for phage and prokaryote assemblages, confirming previous reports [20,

$32263,64]$.

323 Even though we observed in the ordination-plots the distinction of OMZ and oxic mesopelagic 324 (Oxic MES) stations for giruses and pico-eukaryote assemblages (Figure 2, diamond and down triangle), we could not disentangle the effect of oxygen from the other variables included in the analyses (Table 1, complete analysis in Supplementary Material Table 3). This result shows

327 that these assemblages are probably affected by a combination of the predictors evaluated, reflecting their need to cope with a broader environmental gradient that maximizes their nichespace partitioning. Previous studies have identified oxygen as one of the main drivers of the eukaryotic community structure in OMZ regions $[65,22,23]$. These studies mainly compared community composition along the oxygen gradient within the water column depth, from the surface downwards. However, depth stratification of plankton communities is evident even in regions with high oxygen concentrations, so distinct parameters co-varying with depth must be taken into account in addition to the oxygen gradients [66].

In addition to the physicochemical parameters, our results show that particle flux derived from UVP measurements was also a significant variable structuring the phage assemblages in both epipelagic and mesopelagic layers (Table 1, complete analysis in Supplementary Material

338 Table 3). This data supports previous reports about the high correlation of this environmental factor with phages, finding possible relevance for the carbon pump's functioning in epipelagic layers [67]. This observation may also reflect the association with virus inputs from overlaying water layers via sinking particles [68].

342 In situ physico-chemical measurements have revealed the dynamics and fluctuating nature of 343 the ocean, even at short time scale [69]. The heterogeneity in mesopelagic layers given by 344 deep currents, and by the impact of the surface production, together with the low mixing levels, may favor a diversification in the mesopelagic community living in different water masses, leading to species adaptation-acclimation. The Tara Oceans expedition route included 
samples from common or distinct water masses defined by temperature/salinity profiles - T/S, comprising regionally connected or unconnected stations. We identified nine different water masses in the mesopelagic sampled locations (Figure 3). We could confirm significant differences in mesopelagic communities sampled in different water masses based on the PERMANOVA test (Table 2). This result indicates that the oceanic patchiness created by distinct water masses can favor beta-diversity diversification, indicating it to be a critical component for mesopelagic community variation for all the assemblages studied (phages, giruses, prokaryotes, and pico-eukaryotes). Thus, we hypothesize that this result may be explained by two non-exclusive causes related to water masses: (i) past common origin among water masses that have drifted or (ii) constant connectivity by ocean circulation between sampled sites belonging to the same water mass.

Following the biotic control suggested by the deterministic model previously identified, we addressed another lingering question, resolving planktonic community signatures of Oxic MES and OMZ regions for epipelagic communities. For this, we classified OTUs based on their relative abundance into three eco-regions: 1) EPI, 2) Oxic MES, and 3) OMZ. OTUs were classified as Core MES when commonly present in Oxic MES and OMZ samples. The taxa that were either equally abundant in all three eco-regions or not statistically confirmed to a single eco-region were classified as ubiquitous (Supplementary Figure 3). Using this approach, we could identify ubiquitous taxa, that are likely to thrive in a wide range of environmental conditions, or that may be detected in mesopelagic samples due to the simple vertical movement of sinking particles. This classification should help avoid putative biases inherent of the metabarcoding methodology.

More specifically, we were able to identify Oxic MES and OMZ signatures mainly at the infra-

370 taxonomic level (OTU-species) for all biotic groups investigated (Figure 4, Supplementary 371 Figure $3,4,5,6,7)$. This reflected the wide ecological niche occupied by the different species 372 at a higher taxonomic level (i.e. family). At the species level, we observed large taxonomic 373 plasticity of OTUs that occurred equally in both Oxic MES and OMZ samples, called Core MES, 
principally for girus assemblages. However, most OTUs are not yet classified at the infrataxonomic level (data not shown). This observation reflects the knowledge gap about the biodiversity and functional plasticity of species thriving in this ecosystem.

The great majority of phage taxa occurred at similar abundance in all regions (ubiquitous)

378 (Supplementary Figure 3, 4). Surprisingly, this ubiquity is vertically linked at each independent 379 station (Supplementary Figure 4), supporting the seed-bank hypothesis raised by Brum et al. 380 [60], and the correlation to the sinking particles observed here. We observed taxa specific to 381 the mesopelagic layer in second place, mostly related to the OMZ eco-region (Figure 4a, 382 Supplementary Figures 3,8 ). This mesopelagic specificity agrees with the sharp increase in marine phage microdiversity following depth, as previously shown by Gregory et al. [8]. Our results emphasize that one cause for phage stratification in the water column might be the adaptation to the mesopelagic environment. Two hypotheses arise here, 1) the environment acts as a strong driver, directly selecting phages independently of their hosts, and 2) there is higher phage-host specificity in the mesopelagic layer, promoting phage selection. Following the first hypothesis, we can posit that the environment can directly impact phage assemblage composition. The direct contact with the environment of free phage particles (released from their hosts) may reduce infectivity, degrade, or remove virus particles, and adversely affect adsorption to the host [70]. This direct environmental effect over marine phages was reported 392 for different ionic gradients [71], daylight conditions, and temperature [72]. However, the enrichment of prokaryotic OTUs specific to mesopelagic regions (Supplementary Figures 3, 8), especially in OMZs, does not exclude the phage-host indirect selection relationship.

We found fewer but abundant mesopelagic-specific girus OTUs in both Oxic and OMZ ecoregions, indicating that giruses can be less diverse in the mesopelagic layer (Figure 4b,

397 Supplementary Figures 5, 3, 8). Also, giruses can encode genes such as transporters for 398 ammonium, magnesium, and phosphate that are important in marine oligotrophic areas [73]. 399 This characteristic can improve the host's fitness in the short-term but ultimately favor girus 400 fecundity and endurance. This property is named NCLDV-mediated host reprogramming [73]. 
401 The great majority of mesopelagic girus OTUs were assigned to the Core MES group, 402 indicating that these entities may infect a wide range of hosts adapted to diverse environmental 403 conditions.

404 We could better distinguish the prokaryotic mesopelagic signatures between Oxic MES and $405 \mathrm{OMZ}$, confirming the influence of oxygen reported here and in previous studies $[18,19,20]$ 406 (Figure 4c, Supplementary Figures 6, 3, 8). Among the planktonic microorganisms, 407 prokaryotes have been, so far, the most investigated group in OMZ regions, especially in the 408 Pacific Ocean $[60,19,18]$. We observed similar occurrence and abundance for the OMZ 409 signature taxa in the Indian Ocean stations $(1 \mathrm{O}-037,038,039)$ and in stations PO $-100,137$, and 138 from the Pacific Ocean (Figure 4c). These Pacific stations are located in the open 411 ocean (PO - 137 and 138 located in the Equatorial upwelling zone and station PO - 100 in the 412 South Pacific Subtropical Gyre). They present a strong upwelling signature, disclosing an 413 intense decrease in oxygen concentration almost reaching shallow waters. Likewise, the 414 sampling stations in the Indian Ocean are located in well-stratified waters, markedly 415 characterized by the abrupt decrease of oxygen concentration below the thermohaline at 100$416120 \mathrm{~m}$ depth. In all these stations, the oxygen concentration ranges from 0.83 to $3 \mu \mathrm{mol} / \mathrm{kg}$, characterizing functionally anoxic waters since this oxygen level cannot sustain aerobic 418 metabolisms [74]. The other OMZ stations in the Pacific Ocean (PO - 102, 109, 110, 111) are 419 located in coastal areas. Although they are also under the influence of upwellings presenting 420 an oxygen depletion, the oxygen level does not achieve anoxic conditions, and thus are 421 classified as suboxic waters. This microoxic environment is enough to completely change the 422 microbial metabolism delineating the community composition in those sites. Also, differences 423 in offshore and coastal upwelling formation, for instance, or the influence of river runoffs, 424 transporting anthropogenic nutrient enrichment from the continent to coastal zones [74], could 425 be crucial to support the differences in OMZ communities we observed.

426 The same combination of OMZ anoxic and suboxic samples was observed for the pico427 eukaryotic groups MALV-II and Diplonemida, suggesting these OTUs as the true OMZ 
eukaryotic signatures (Figure 4d). Some OTUs of these groups exhibited similar occurrences

in the anoxic Indian and Pacific Oceans but not in suboxic samples from the Pacific Ocean. However, we observed a lower number of pico-eukaryotic taxa in the $\mathrm{OMZ}$ eco-region, the prevailing OTUs being specific to Oxic MES locations in most cases. Although the CCA analysis did not disentangle the oxygen from the other variables to explain the pico-eukaryote assemblage variations, here we can verify that $\mathrm{OMZ}$ conditions do act negatively on selection of pico-eukaryotes in marine environments.

Another step to better understand mesopelagic community dynamics is to dissect the ecological relationships among species that thrive in this layer. Co-occurrence networks can indicate how the environment may structure the community acting as a filter for resident species [76]. They can also give us glimpses of organisms' ecological interactions based on species connectivity $[76,77]$. Combining the girus, prokaryote, and pico-eukaryote data, we inferred a network containing 6,154 nodes and 12,935 edges (Figure 5a, Table 3). Due to the lower number of stations sampled for phages, we excluded this group from the analysis. We

442 found mainly positive relationships (94\%), suggesting a predominance of putative biotic 443 interactions (e.g. competition, symbiosis) rather than taxa avoidance or exclusion. This dominance of positive relations was also reported for epipelagic plankton communities $[27,78]$.

445 The global network had a modularity value greater than 0.4 (Table 3), indicating that the 446 network has a modular structure [74]. Using a module detection algorithm, we were able to 447 identify 36 distinct modules in the global network. Three of them were mainly composed of 448 OTUs significantly enriched in mesopelagic OTUs (Oxic MES enriched module 1 and OMZ 449 enriched modules 4 and 17; Figure 5). Together, these three modules cover almost the total 450 richness found in the mesopelagic zone (Figure 5b), and present similar values for the average 451 degree, clustering coefficient, and average path length (Table 3). These parameters indicate 452 a network complexity [76], hinting at distinct ecological niches within the mesopelagic at the 453 level of investigated organismal fractions. 
454 In more detail, the $\mathrm{OMZ}$ signature modules were composed of a few connected nodes (323

455 and 175 nodes for modules 4 and 17, respectively), potentially indicating two distinct OMZ 456 community niches. The Oxic MES module 1 counted more nodes composing the network 457 associations (731 nodes), and both modules presented a variation in taxonomic composition 458 and proportions. OMZ module 4 contained mainly prokaryotic (23\%) and girus (55\%) OTUs 459 (Figure 5c, d). Among the prokaryotes, we detected taxa previously determined as OMZ 460 signatures (Nitrospinae, Marinimicrobia SAR 406, and Planctomycetes). Module 17 is mainly comprised of pico-eukaryotes (82\%), notably MALV-II (14\%) and Diplonemida (17\%) previously indicated as $\mathrm{OMZ}$ signatures. Module 1 is taxonomically more diverse but is mainly comprised of giruses and pico-eukaryotes. These groups accounted for $36 \%$ and $55 \%$, respectively, of OTUs in this module (Figure 5c, d). Giruses contributed to 598 associations (edges) in mesopelagic module 1, of which 177 occurred between giruses and picoeukaryotes. Giruses from the Mimiviridae family are the most numerous taxa in all three mesopelagic modules. Mimiviridae is a very abundant family in the ocean, present in various size ranges from piconanoplankton $(0.8-5 \mu \mathrm{m})$ up to mesoplankton $(180-2,000 \mu \mathrm{m})[9,79]$. This observation supports our findings that giruses are a prosperous group in mesopelagic waters, undertaking different strategies to endure in such environmental conditions. In all three modules, we observed the presence of Foraminifera, of which some species can use nitrate over oxygen as an electron acceptor, favoring their survival in OMZ regions [80]. pattern in communities, and this assertion is valid for small assemblages and for large ensembles. Consistently, the observation of three distinct community modules supports the evidence of the lognormal ecological model empirically defined locally for each assemblage.

477 Our results converge and suggest that the mesopelagic presents at least three well-defined 478 ecological niches (Oxic MES, OMZ-4 and OMZ-17), with established conditions and resources 479 (abiotic and biotic) that allow the survival of a given species in these environments. Differences 
481

482

483

484

485

486

487

488

489

490

491

492

493

494

495

496

497

498

499

500

501

502

503

504

505

506

507

among mesopelagic community members, directly affecting ecosystem stability due to habitat change.

\section{Conclusions}

In this study, we explored mesopelagic pico-plankton ecological structuring, and concluded that this component of oceanic plankton is heterogeneous regarding its environmental parameters. The ecological parameters drive mesopelagic community assemblages, as they fit niche ecological models. Although we could not identify a single driver of community composition (such as temperature for sunlit ocean) for all organisms, we could pinpoint the relevance of oxygen for phages and prokaryotic fractions and the relation of the former with particle flux. Also, we show that water masses defined by their T/S profiles can explain the differences in the observed pico-plankton structure, pointing to the role of a set of environmental parameters rather than single drivers for community composition.

By establishing Eco-regions (Epipelagic, Oxic MES, and OMZ), we were able to discriminate specific OTUs for all fractions studied. While we recovered known markers for Oxic MES and OMZ regions at high taxonomic levels, we also found that most of these OTU signatures are observed at low taxonomic levels, which sometimes cannot be resolved using current databases. Crossing these specific OTUs with co-occurrence networks, we identified three niches with biotic and abiotic conditions that characterize mesopelagic waters.

The limiting access to data is usually the bottleneck for knowledge about mesopelagic dynamics. Our study benefits from a more significant number of organism samples and distinct oceanic provinces than previous ones, allowing us to combine data to derive an expanded vision of mesopelagic composition. Our results emphasize the need for better understanding of mesopelagic life, in particular by improving our knowledge about oxic and oxygen-depleted mesopelagic-dwelling communities, especially as climate change can be expected to expand marine OMZs shortly. 


\section{Acknowledgments}

This study is part of the "Ocean Plankton, Climate and Development" project conducted by the Tara Ocean Foundation with the support of the French Facility for the Global Environment (FFEM). Rigonato J., Budinich M., Murillo A.A., Brandão M.C., Pierella Karlusich J.J. and Soviadan Y.D. received financial support from FFEM to execute the project. Brandão, M.C. also received financial support from Coordination for the Improvement of Higher Education Personnel of Brazil (CAPES 99999.000487/2016-03). Tara Oceans (which includes both the Tara Oceans and Tara Oceans Polar Circle expeditions) would not exist without the leadership of the Tara Ocean Foundation and the continuous support of 23 institutes (https://fondationtaraocean.org). We further thank the commitment of the following sponsors: CNRS (in particular Groupement de Recherche GDR3280 and the Research Federation for the study of Global Ocean Systems Ecology and Evolution, FR2022/Tara Oceans-GOSEE), European Molecular Biology Laboratory (EMBL), Genoscope/CEA, The French Ministry of Research, and the French Government 'Investissements d'Avenir' programs OCEANOMICS (ANR- 11-BTBR-0008), FRANCE GENOMIQUE (ANR-10-INBS-09-08), MEMO LIFE (ANR10-LABX-54), and PSL* Research University (ANR-11-IDEX-0001-02). We also thank the support and commitment of agnès b. and Etienne Bourgois, the Prince Albert II de Monaco Foundation, the Veolia Foundation, Region Bretagne, Lorient Agglomeration, Serge Ferrari, World Courier. The global sampling effort was enabled by countless scientists and crew who sampled aboard the schooner Tara from 2009-2013, and we thank MERCATOR-CORIOLIS and ACRIST for providing daily satellite data during the expeditions. We are also grateful to the countries who graciously granted sampling permission. The authors declare that all data reported herein are fully and freely available from the date of publication, with no restrictions, and that all of the analyses, publications, and ownership of data are free from legal entanglement or restriction by the various nations whose waters the Tara Oceans expeditions sampled in. This article is contribution number XX of Tara Oceans. 
Tara Oceans Coordinators (alphabetical order) Silvia G. Acinas, Marcel Babin, Peer Bork,

Pesant, Nicole Poulton, Jeroen Raes, Christian Sardet, Sabrina Speich, Lars Stemmann,

Matthew B. Sullivan, Shinichi Sunagawa and Patrick Wincker.

\section{Conflict of Interest}

The authors declare that they have no conflict of interest.

\section{References}

1. Proud R, Cox MJ, and Brierley AS. Biogeography of the Global Ocean's Mesopelagic Zone. en. Current Biology 2017 Jan; 27:113-9. doi: 10.1016/j.cub.2016.11.003

2. Robinson C, Steinberg DK, Anderson TR, Ar'istegui J, Carlson CA, Frost JR, et al. Mesopelagic zone ecology and biogeochemistry - a synthesis. en. Deep Sea Research Part II: Topical Studies in Oceanography 2010 Aug; 57:1504-18. doi: 10.1016/j.dsr2.2010.02.018

3. Mestre M, Ruiz-Gonz'alez C, Logares R, Duarte CM, Gasol JM, and Sala MM. Sinking particles promote vertical connectivity in the ocean microbiome. en. Proceedings of the National Academy of Sciences 2018 Jul; 115:E6799-E6807. doi: 10.1073/pnas.1802470115

4. Whitman WB, Coleman DC, and Wiebe WJ. Prokaryotes: The unseen majority. en. Proceedings of the National Academy of Sciences 1998 Jun; 95:6578-83. doi: 10.1073/pnas.95.12.6578

5. Hidalgo $\mathrm{M}$ and Browman HI. Developing the knowledge base needed to sustainably manage mesopelagic resources. en. ICES Journal of Marine Science 2019 May; 76:609-15. doi: 10.1093/icesjms/fsz067

6. St. John MA, Borja A, Chust G, Heath M, Grigorov I, Mariani P, et al. A Dark Hole in Our Under- standing of Marine Ecosystems and Their Services: Perspectives from the Mesopelagic Community. en. Frontiers in Marine Science 2016 Mar; 3. doi: 10.3389/fmars.2016.00031

7. Glover AG, Wiklund $H$, Chen $C$, and Dahlgren TG. Managing a sustainable deep-sea 'blue economy' requires knowledge of what actually lives there. eLife 2018 Nov; 7. Ed. by Groll $\mathrm{H}$ and Rodgers PA:e41319. doi: 10.7554/eLife.41319

8. GregoryAC, ZayedAA, Conceição-NetoN, TempertonB, BolducB, AlbertiA, et al. MarineDNA Viral Macro- and Microdiversity from Pole to Pole. en. Cell $2019 \mathrm{Apr}$ :S0092867419303411. doi: 10.1016/j.cell.2019.03.040 
9. Endo H, Blanc-Mathieu R, Li Y, Salazar G, Henry N, Labadie K, et al. Biogeography of marine giant viruses reveals their interplay with eukaryotes and ecological functions. en. Nature Ecology \& Evolution 2020 Sep. doi: 10.1038/s41559-020-01288-w

10. Sunagawa S, Coelho LP, Chaffron S, Kultima JR, Labadie K, Salazar G, et al. Structure and function of the global ocean microbiome. en. Science 2015 May; 348:12613591261359. doi: 10.1126/science. 1261359

11. Salazar G, Paoli L, Alberti A, Huerta-Cepas J, Ruscheweyh HJ, Cuenca M, et al. Gene Expression Changes and Community Turnover Differentially Shape the Global Ocean Metatranscriptome. en. Cell 2019 Nov; 179:1068-1083.e21. doi: 10.1016/j.cell.2019.10.014

12. Giner CR, Pernice MC, Balagu'e V, Duarte CM, Gasol JM, Logares R, et al. Marked changes in diversity and relative activity of picoeukaryotes with depth in the world ocean. en. The ISME Journal 2020 Feb; 14:437-49. doi: 10.1038/s41396-019-0506-9

13. Ibarbalz FM, Henry N, Brand ao MC, Martini S, Busseni G, Byrne H, et al. Global Trends in Marine Plankton Diversity across Kingdoms of Life. en. Cell 2019 Nov; 179:10841097.e21. doi: 10.1016/j. cell.2019.10.008

14. Capone DG and Hutchins DA. Microbial biogeochemistry of coastal upwelling regimes in a changing ocean. en. Nature Geoscience 2013 Sep; 6:711-7. doi: 10.1038/ngeo1916

15. Breitburg D, Levin LA, Oschlies A, Gr'egoire M, Chavez FP, Conley DJ, et al. Declining oxygen in the global ocean and coastal waters. en. $2018: 13$

16. Stevens $\mathrm{H}$ and Ulloa $\mathrm{O}$. Bacterial diversity in the oxygen minimum zone of the eastern tropical South Pacific. en. Environmental Microbiology 2008 May; 10:1244-59. doi: 10.1111/j.1462-2920.2007. 01539.x

17. Stewart FJ, Ulloa O, and DeLong EF. Microbial metatranscriptomics in a permanent marine oxygen minimum zone: OMZ community gene expression. en. Environmental Microbiology 2012 Jan; 14:23- 40. doi: 10.1111/j.1462-2920.2010.02400.x

18. Ulloa O, Wright JJ, Belmar L, and Hallam SJ. Pelagic Oxygen Minimum Zone Microbial Communities. en. The Prokaryotes. Ed. by Rosenberg E, DeLong EF, Lory S, Stackebrandt E, and Thompson F. Berlin, Heidelberg: Springer Berlin Heidelberg, 2013 :113-22. doi: 10.1007/978-3-642-30123-0_45

19. Ulloa $O$ and Pantoja S. The oxygen minimum zone of the eastern South Pacific. en. Deep Sea Research Part II: Topical Studies in Oceanography 2009 Jul; 56:987-91. doi: 10.1016/j.dsr2.2008.12.004

20. Wright JJ, Konwar KM, and Hallam SJ. Microbial ecology of expanding oxygen minimum zones. en. Nature Reviews Microbiology 2012 Jun; 10:381-94. doi: $10.1038 /$ nrmicro2778

21. Duret MT, Pachiadaki MG, Stewart FJ, Sarode N, Christaki U, Monchy S, et al. Sizefractionated diversity of eukaryotic microbial communities in the Eastern Tropical North Pacific oxygen minimum zone. en. FEMS Microbiology Ecology 2015 May; 91. doi: 10.1093/femsec/fiv037

22. Orsi W, Song YC, Hallam S, and Edgcomb V. Effect of oxygen minimum zone formation on communities of marine protists. en. The ISME Journal 2012 Aug; 6:1586-601. doi: 10.1038/ismej.2012.7

23. Parris DJ, Ganesh S, Edgcomb VP, DeLong EF, and Stewart FJ. Microbial eukaryote diversity in the marine oxygen minimum zone off northern Chile. en. Frontiers in Microbiology 2014 Oct; 5. doi: 10.3389/fmicb.2014.00543 
24. Rusch DB, Halpern AL, Sutton G, Heidelberg KB, Williamson S, Yooseph S, et al. The Sorcerer II Global Ocean Sampling Expedition: Northwest Atlantic through Eastern Tropical Pacific. en. PLOS Biology 2007 Mar; 5:e77. doi: 10.1371/journal.pbio.0050077

25. Karsenti E, Acinas SG, Bork P, Bowler C, De Vargas C, Raes J, et al. A Holistic Approach to Marine Eco-Systems Biology. en. PLoS Biology 2011 Oct; 9:e1001177. doi: 10.1371/journal.pbio.1001177

26. Pernice MC, Forn I, Gomes A, Lara E, Alonso-S'aez L, Arrieta JM, et al. Global abundance of planktonic heterotrophic protists in the deep ocean. en. The ISME Journal 2015 Mar; 9:782-92. doi: 10.1038/ismej.2014.168

27. Lima-Mendez G, Faust K, Henry N, Decelle J, Colin S, Carcillo F, et al. Determinants of community structure in the global plankton interactome. en. Science 2015 May; 348:1262073-1262073. doi: 10. 1126/science.1262073

28. Louca S, Hawley AK, Katsev S, Torres-Beltran M, Bhatia MP, Kheirandish S, et al. Integrating bio- geochemistry with multiomic sequence information in a model oxygen minimum zone. en. Proceedings of the National Academy of Sciences 2016 Oct; 113:E5925-E5933. doi: 10.1073/pnas.1602897113

29. Ardyna M, Tara Oceans Consortium C, and Tara Oceans Expedition P. Environmental context of all station from the Tara Oceans Expedition (2009-2013), about the annual cycle of key parameters estimated daily from remote sensing products at a spatial resolution of $9 \mathrm{~km}$. en. type: dataset. 2017. doi: 10.1594/PANGAEA.883613

30. Sunagawa, S., Acinas, S. G., Bork, P., Bowler, C., Acinas, S. G., Babin, M., ... de Vargas, C. (2020). Tara Oceans: towards global ocean ecosystems biology. Nature Reviews Microbiology, 18(8), 428-445. doi: 10.1038/s41579-020-0364-5

31. Guidi L, Morin P, Coppola L, Tremblay JE, Pesant S, Tara Oceans Consortium C, et al. Environmental context of all samples from the Tara Oceans Expedition (2009-2013), about nutrients in the targeted environmental feature. en. type: dataset. 2017. doi: 10.1594/PANGAEA.875575

32. Guidi L, Picheral M, Pesant S, Tara Oceans Consortium C, and Tara Oceans Expedition P. Environ- mental context of all samples from the Tara Oceans Expedition (2009-2013), about sensor data in the targeted environmental feature. en. type: dataset. 2017. doi: 10.1594/PANGAEA.875576

33. Guidi L, Ras J, Claustre H, Pesant S, Tara Oceans Consortium C, and Tara Oceans Expedition P. Environmental context of all samples from the Tara Oceans Expedition (2009-2013), about pigment concentrations (HPLC) in the targeted environmental feature. en. type: dataset. 2017. doi: 10.1594/PANGAEA.875569

34. Pesant S, Tara Oceans Consortium C, and Tara Oceans Expedition P. Methodology used on board to prepare samples from the Tara Oceans Expedition (2009-2013). en. type: dataset. 2017. doi: 10.1594/ PANGAEA.875580

35. Speich S, Chaffron S, Ardyna M, Pesant S, Tara Oceans Consortium C, and Tara Oceans Expedition $P$. Environmental context of all samples from the Tara Oceans Expedition (2009-2013), about the water column features at the sampling location. en. type: dataset. 2017. doi: 10.1594/PANGAEA.875579

36. Picheral M, Guidi L, Stemmann L, Karl DM, Iddaoud G, and Gorsky G. The Underwater Vision Profiler 5: An advanced instrument for high spatial resolution studies of particle size spectra and zooplankton. Limnology and Oceanography: Methods 2010; 8:462-73

37. Picheral M, Searson S, Taillandier V, Bricaud A, Boss E, Ras J, et al. Vertical profiles of environmental parameters measured on discrete water samples collected with Niskin bottles during the Tara Oceans expedition 2009-2013. en. type: dataset. 2014. doi: 10.1594/PANGAEA.836319 
38. Schlitzer R. Interactive analysis and visualization of geoscience data with Ocean Data View. en. Computers \& Geosciences 2002 Dec; 28:1211-8. doi: 10.1016/S00983004(02)00040-7

39. Pesant, S., Not, F., Picheral, M., Kandels-Lewis, S., Le Bescot, N., Gorsky, G., ... Searson, S. (2015). Open science resources for the discovery and analysis of Tara Oceans data. Scientific Data, 2(Lmd), 1-16. doi: $10.1038 /$ sdata.2015.23

40. Alberti A, Poulain J, Engelen S, Labadie K, Romac S, Ferrera I, et al. Viral to metazoan marine plankton nucleotide sequences from the Tara Oceans expedition. en. Scientific Data 2017 Aug; 4:170093. doi: 10.1038/sdata.2017.93

41. Vargas C de, Audic S, Henry N, Decelle J, Mahe F, Logares R, et al. Eukaryotic plankton diversity in the sunlit ocean. en. Science 2015 May; 348:1261605-1261605. doi: 10.1126/science. 1261605

683

684

685

686

687

688

689

690

691

692

693

694

695

696

697

698

699

700

701

702

703

704

705

706

707

708

709

710

711

712

713

714

715

716

717

42. Jari Oksanen FGB, Friendly $M$, Kindt R, Legendre $P$, McGlinn D, Minchin PR, et al. vegan: Community Ecology Package. R package version 2.5-6. 2019

43. Wilson JB. Methods for fitting dominance/diversity curves. en. Journal of Vegetation Science 1991 Feb; 2:35-46. doi: 10.2307/3235896

44. Matthews TJ and Whittaker RJ. Fitting and comparing competing models of the species abundance distribution: assessment and prospect. en. Frontiers of Biogeography 2014 Jun; 6. doi: 10.21425/ F56220607

45. Chave J. Neutral theory and community ecology: Neutral theory and community ecology. en. Ecology Letters 2004 Feb; 7:241-53. doi: 10.1111/j.14610248.2003.00566.x

46. McGill BJ, Maurer BA, and Weiser MD. EMPIRICAL EVALUATION OF NEUTRAL THEORY. en. Ecology 2006 Jun; 87:1411-23. doi: 10.1890/00129658(2006)87[1411:EEONT]2.0.CO;2

47. Paulo I. Prado MDM and Chalom A. sads:Maximum Likelihood Models for Species Abundance Distributions. $R$ package version 0.4.2. 2018

48. Magurran AE and McGill BJ. Biological Diversity frontiers in measurement and assessment. en. 24. New York: Oxford University press, 2011

49. Burnham, K. P., \& Anderson, D. R. (2004). Multimodel inference: Understanding AIC and BIC in model selection. Sociological Methods and Research, 33(2), 261-304. doi: 10.1177/0049124104268644

50. R Core Team. R: A Language and Environment for Statistical Computing. ISBN 3900051-07-0. R Foundation for Statistical Computing. Vienna, Austria, 2013

51. Dinno A. Dunn's Test of Multiple Comparisons Using Rank Sums. R package version 1.3.5. 2017

52. Tackmann J, Rodrigues JFM, and Mering C von. Rapid inference of direct interactions in large-scale ecological networks from heterogeneous microbial sequencing data. Cell Systems 2019. doi: 10.1016/ j.cels.2019.08.002

53. Clauset, Newman, and Moore, "Finding Community Structure in Very Large Networks." Physical Review E. 2004; 70:066111 doi: 10.1103/PhysRevE.70.066111

54. Vellend M. Conceptual Synthesis in Community Ecology. en. The Quarterly Review of Biology 2010 Jun; 85:183-206. doi: 10.1086/652373

55. Filho RC, Martins FR, and Gneri MA. Fitting abundance distribution models in tropical arboreal communities of SE Brazil. en. Community Ecology 2002; 3:169-80

56. Magurran $\mathrm{AE}$ and Henderson PA. Explaining the excess of rare species in natural species abundance distributions. en. 2003; $422: 3$ 
57. Sugihara G. Minimal Community Structure: An Explanation of Species Abundance Patterns. en. The American Naturalist 1980; 116:770-87

58. Bulmer MG. On Fitting the Poisson Lognormal Distribution to Species-Abundance Data. en. Biometrics 1974 Mar; 30:101. doi: 10.2307/2529621

59. Preston FW. The Commonness, And Rarity, of Species. en. Ecology 1948 Jul; 29:25483. doi: $10.2307 / 1930989$

60. Ser-Giacomi, E., Zinger, L., Malviya, S., De Vargas, C., Karsenti, E., Bowler, C., \& De Monte, S. (2018). Ubiquitous abundance distribution of non-dominant plankton across the global ocean. Nature Ecology and Evolution, 2(8), 1243-1249. doi: 10.1038/s41559018-0587-2

61. Brum JR, Ignacio-Espinoza JC, Roux S, Doulcier G, Acinas SG, Alberti A, et al. Patterns and ecological drivers of ocean viral communities. en. Science 2015 May; 348:1261498-1261498. doi: 10 . 1126 / science.1261498

62. Ghiglione JF, Galand PE, Pommier T, Pedrós-Alió C, Maas EW, Bakker K, et al. Poleto-pole bio- geography of surface and deep marine bacterial communities. en. Proceedings of the National Academy of Sciences 2012 Oct; 109:17633-8. doi: 10.1073/pnas.1208160109

63. Ulloa O, Canfield DE, DeLong EF, Letelier RM, and Stewart FJ. Microbial oceanography of anoxic oxygen minimum zones. en. Proceedings of the National Academy of Sciences 2012 Oct; 109:15996- 6003. doi: 10.1073/pnas.1205009109

64. Aldunate $M$, De la Iglesia R, Bertagnolli $A D$, and Ulloa O. Oxygen modulates bacterial community composition in the coastal upwelling waters off central Chile. en. Deep Sea Research Part II: Topical Studies in Oceanography 2018 Oct; 156:68-79. doi: 10.1016/j.dsr2.2018.02.001

65. De la Iglesia R, Echenique-Subiabre I, Rodríguez-Marconi S, Espinoza JP, Dassow P von, Ulloa $\mathrm{O}$, et al. Distinct oxygen environments shape picoeukaryote assemblages thriving oxygen minimum zone waters off central Chile. en. Journal of Plankton Research 2020 Sep; 42. Ed. by Dolan J:514-29. doi: 10.1093/plankt/fbaa036

66. Schnetzer A, Moorthi SD, Countway PD, Gast RJ, Gilg IC, and Caron DA. Depth matters: Microbial eukaryote diversity and community structure in the eastern North Pacific revealed through environmen- tal gene libraries. en. Deep Sea Research Part I: Oceanographic Research Papers 2011 Jan; 58:16-26. doi: 10.1016/j.dsr.2010.10.003

67. Guidi L, Chaffron S, Bittner L, Eveillard D, Larhlimi A, Roux S, et al. Plankton networks driving carbon export in the oligotrophic ocean. en. Nature 2016 Feb; 532:465-70. doi: 10.1038/nature16942

68. Parada V, Sintes E, Aken HM van, Weinbauer MG, and Herndl GJ. Viral Abundance, Decay, and Diversity in the Meso- and Bathypelagic Waters of the North Atlantic. en. Applied and Environmental Microbiology 2007 Jul; 73:4429-38. doi: 10.1128/AEM.00029-07

69. Bates AE, Helmuth B, Burrows MT, Duncan MI, Garrabou J, Guy-Haim T, et al. Biologists ignore ocean weather at their peril. en. Nature 2018 Aug; 560:299-301

70. Mojica KDA and Brussaard CPD. Factors affecting virus dynamics and microbial hostvirus interactions in marine environments. en. FEMS Microbiol Ecol 2014 :21

71. Kukkaro $P$ and Bamford $\mathrm{DH}$. Virus-host interactions in environments with a wide range of ionic trengths. en. Environmental Microbiology Reports $2009: 7$

72. Bettarel $\mathrm{Y}$, Bouvier $\mathrm{T}$, and Bouvy $\mathrm{M}$. Viral persistence in water as evaluated from a tropical/temperate cross-incubation. en. Journal of Plankton Research 2009 Aug; 31:909-16. doi: 10.1093 / plankt / fbp041 
73. Schulz F. Giant virus diversity and host interactions through global metagenomics. en. Nature 2020; 578:432-6. doi: https://doi.org/10.1038/s41586-020-1957-x

74. Thamdrup B, Dalsgaard $T$, and Revsbech NP. Widespread functional anoxia in the oxygen minimum zone of the Eastern South Pacific. en. Deep Sea Research Part I: Oceanographic Research Papers 2012 Jul; 65:36-45. doi: 10.1016/j.dsr.2012.03.001

75. Helly JJ and Levin LA. Global distribution of naturally occurring marine hypoxia on continental margins. en. Deep Sea Research Part I: Oceanographic Research Papers 2004 Sep; 51:1159-68. doi: 10.1016/j.dsr.2004.03.009

76. Berry $\mathrm{D}$ and Widder S. Deciphering microbial interactions and detecting keystone species with co- occurrence networks. en. Frontiers in Microbiology 2014 May; 5. doi: 10.3389/fmicb.2014.00219

77. Zhu W, Qin C, Ma H, Xi S, Zuo T, Pan W, et al. Response of protist community dynamics and co- occurrence patterns to the construction of artificial reefs: A case study in Daya Bay, China. en. Science of The Total Environment 2020 Nov; 742:140575. doi: 10.1016/j.scitotenv.2020.140575

78. Chaffron, S., Delage, E., Budinich, M., Vintache, D., Henry, N., Nef, C., ... Eveillard, D. (2020). Environmental vulnerability of the global ocean plankton community interactome. BioRxiv. doi: 10.1101/2020.11.09.375295

79. Mihara T, Koyano H, Hingamp P, Grimsley N, Goto S, and Ogata H. Taxon Richness of "Megaviridae" Exceeds those of Bacteria and Archaea in the Ocean. en. Microbes and Environments 2018; 33:162-71. doi: 10.1264/jsme2.ME17203

80. Glock N, Roy AS, Romero D, Wein T, Weissenbach J, Revsbech NP, et al. Metabolic preference of nitrate over oxygen as an electron acceptor in foraminifera from the Peruvian oxygen minimum zone. en. Proceedings of the National Academy of Sciences 2019 Feb; 116:2860-5. doi: 10.1073/pnas. 1813887116

Figure legends

Figure 1: Geographical locations of Tara Oceans epipelagic and mesopelagic sampling sites included in this study. Symbols: $\boldsymbol{\Delta}$ refers to epipelagic, $\boldsymbol{\nabla}$ Oxic MES and $\bullet \mathrm{OMZ}$ eco-regions. Symbol colors represent organism groups evaluated in the present study.

Figure 2: Ordination plot of epipelagic (left) and mesopelagic (right) communities based on OTU composition based on canonical correspondence analysis (CCA). Percentages in parentheses are the amount of variation constrained, in titles represent the total in each analysis, and in the axis the correspondent value for each dimension. Arrows represent environmental quantitative explanatory variables with arrowheads indicating their direction of increase. Shapes represent sampling sites. Shape formats represent eco-regions, epi: epipelagic, Oxic MES: oxic mesopelagic, OMZ: oxygen minimum zone mesopelagic. IO: Indian Ocean, NAO: North Atlantic Ocean, NPO: North Pacific Ocean, SAO: South Atlantic Ocean, SPO: South Pacific Ocean.

Figure 3: Temperature and salinity plot indicating water mass designation for all mesopelagic samples. Formats represent the different oceanic basins ( $\boldsymbol{\square}$ - North Atlantic Ocean, $\bullet$ - South Atlantic Ocean, $\boldsymbol{\Delta}$ - Pacific Ocean, $\star$ - Indian Ocean). Colors indicate the oxygen concentration at the sampling depth. LSW - Labrador Sea Water; AAIW - Antarctic Intermediate Water; tNPIW transitional North Pacific Intermediate Water; SAMW - Subantarctic Mode Water; SPSTMW - South Pacific Subtropical Mode Water; modAAIW - modified Antarctic Intermediate Water; PGW - Persian Gulf Water mass; RSW - Red Sea Water mass; NASTMW - North Atlantic Subtropical Mode Water. 
813 Figure 4: Relative abundance of OTUs assigned to mesopelagic eco-regions. A) Phages, B) 814 Giruses, C) Prokaryotes and D) pico-Eukaryotes.

815 Figure 5: Co-occurrence network in epipelagic and mesopelagic communities. A) Global 816 network, with connected modules for OMZ (purple and orange) and MES (green) highlighted. 817 B) Relative taxa abundance in each module in each station and depth. C) Relative number of 818 OTUs classified in taxonomic groups. D) Network representation of modules.

819 Supplementary Figure 1: Non-metric multidimensional scaling (NMDS) showing epipelagic 820 and mesopelagic community stratification for each organism group.

821 Supplementary Figure 2: Epipelagic and mesopelagic group dispersion based on physicalchemical oceanic properties (Euclidian method). A) First two axes of PCoA. B) Dispersion of 823 distances from samples to centroids.

824 Supplementary Figure 3: Relative abundance of OTUs classified into different eco-regions 825 by ocean layers.

826 Supplementary Figure 4: Normalized relative abundance of phages and their preferred eco827 region.

828 Supplementary Figure 5: Normalized relative abundance of giruses and their preferred eco829 region.

830 Supplementary Figure 6: Normalized relative abundance of prokaryotes and their preferred 831 eco-region.

832 Supplementary Figure 7: Normalized relative abundance of pico-eukaryotes and their 833 preferred eco-region.

834 Supplementary Figure 8: Relative abundance of OTUs from taxonomic groups for epipelagic 835 and mesopelagic (Oxic MES and OMZ) samples enriched in each eco-region (UBI: ubiquitous, 836 EPI: epipelagic, Core MES: core mesopelagic, Oxic MES: oxic mesopelagic, OMZ: oxygen minimum zone. A) Phages B) Giruses C) Prokaryotes D) pico-eukaryotes. 


\section{${ }_{611}$ Figures:}

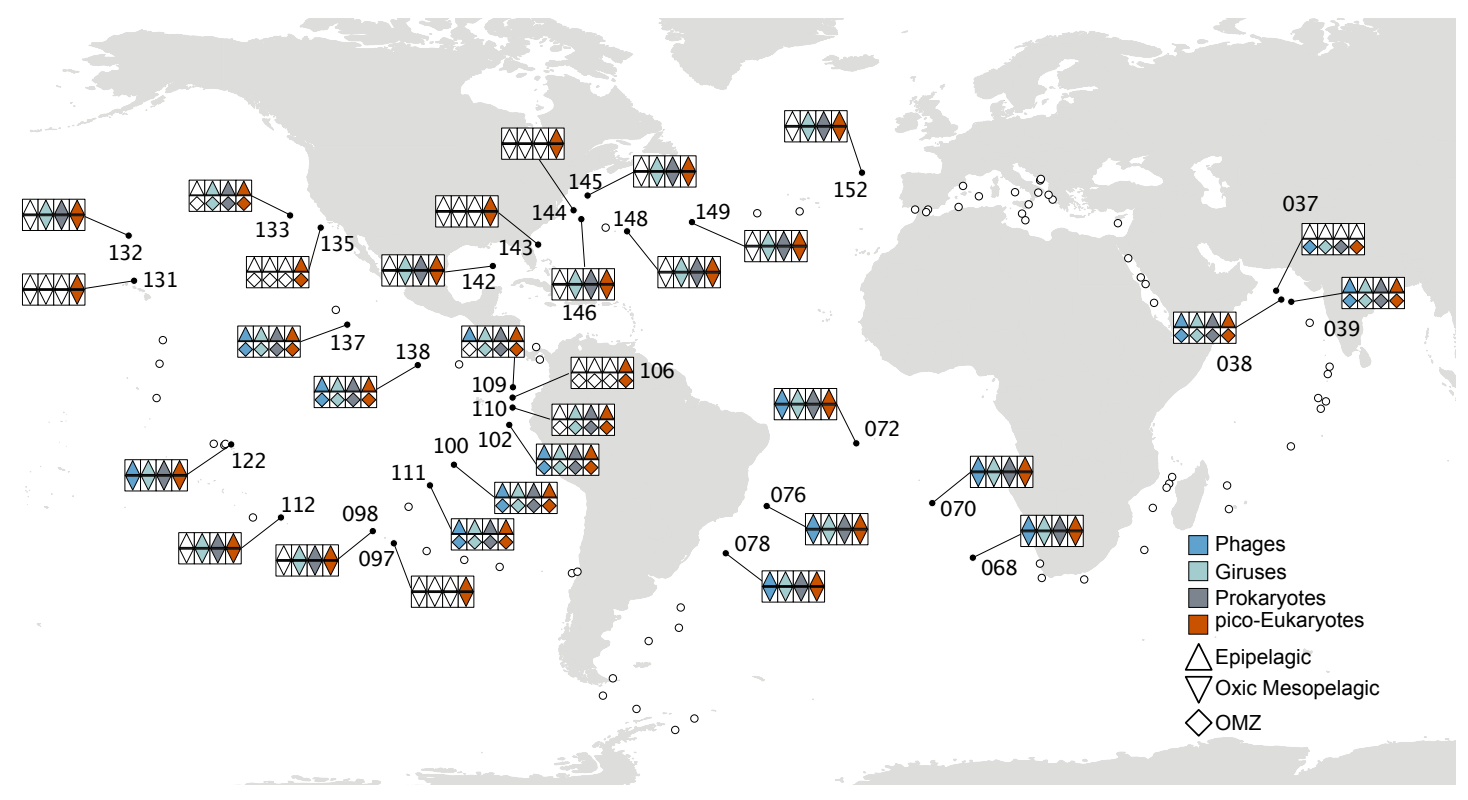

Figure 1: Geographical locations of Tara Oceans epipelagic and mesopelagic sampling sites included in this study. Symbols up-triangle refers to epipelagic, down-triangles Oxic MES and diamond OMZ eco-regions. Symbols colors represent organism groups evaluated in the present study 

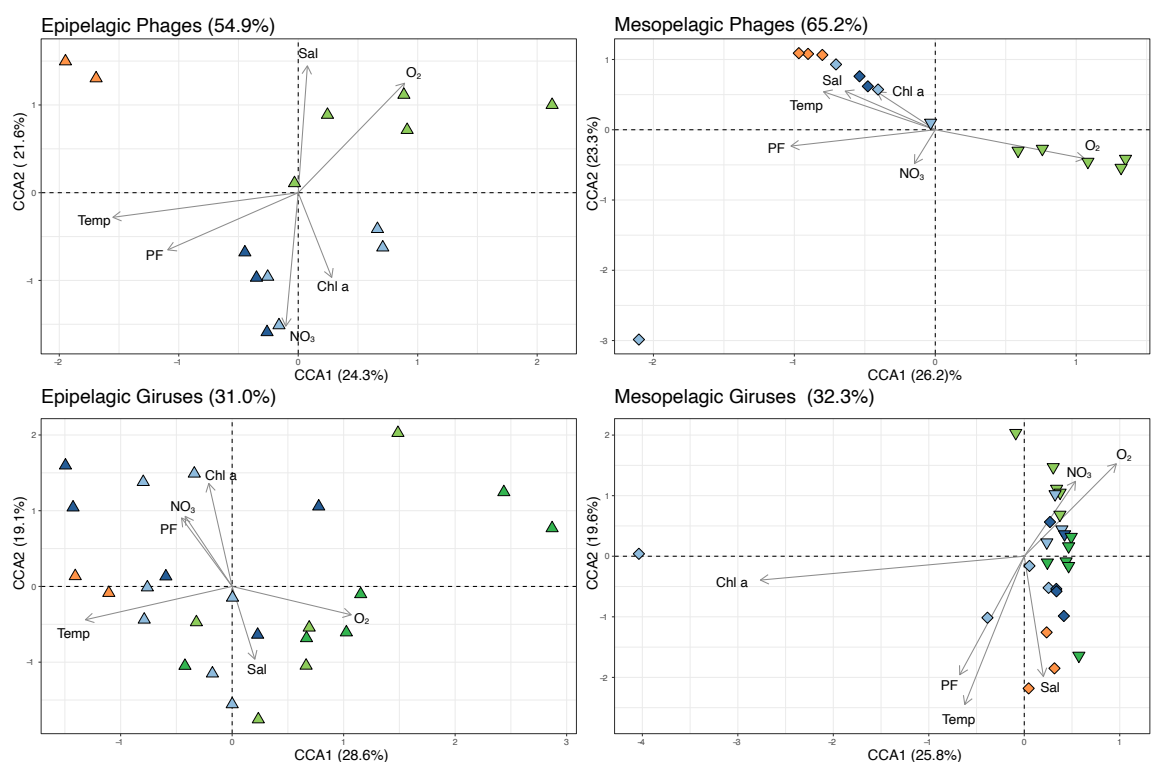

Mesopelagic Giruses (32.3\%)
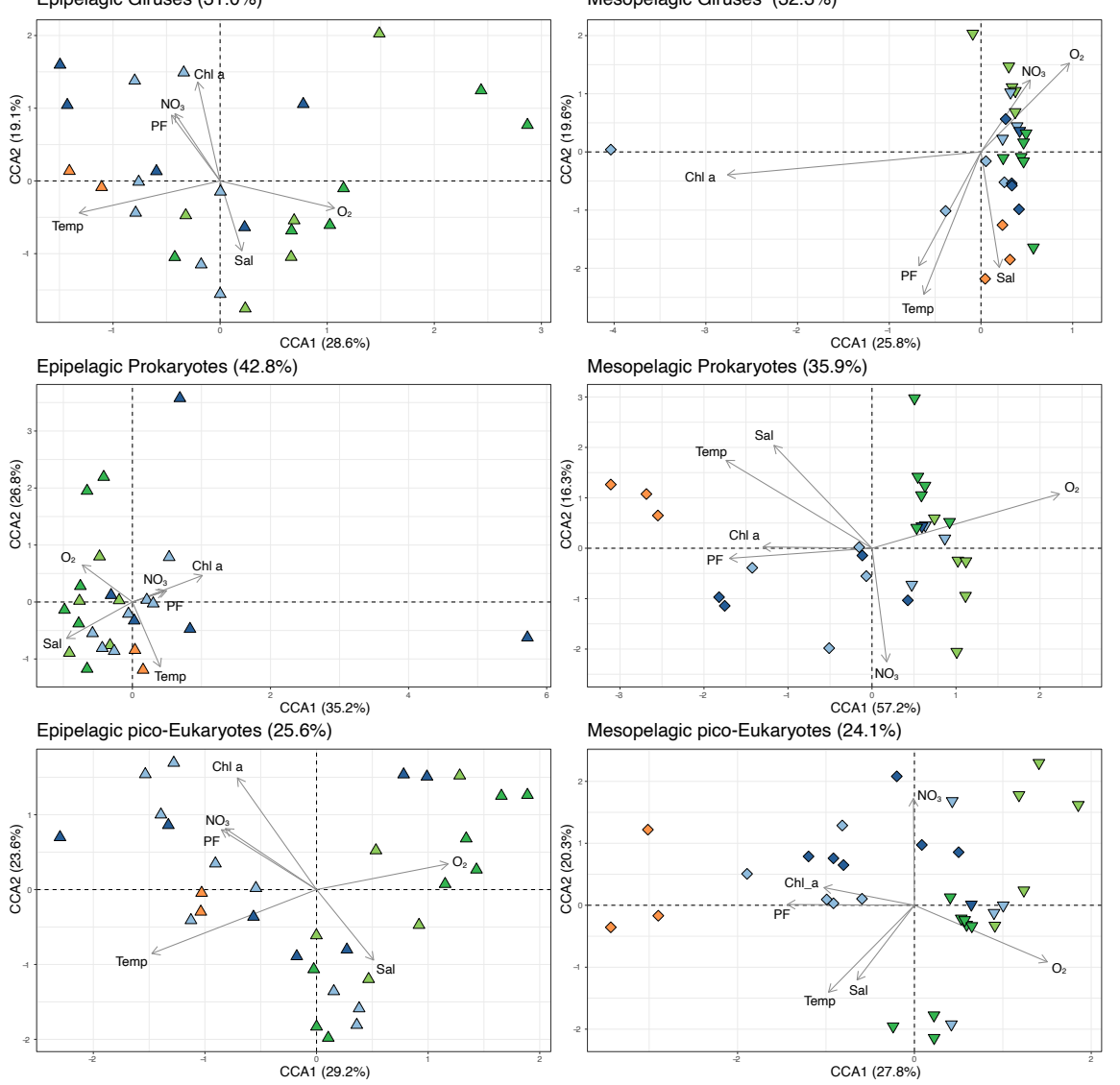

EcoRegions $\triangle$ EPI $\nabla_{\text {MES }}^{\text {OXIC }} \bigcirc \mathrm{OMZ}$

Oceanic Region $\quad \square \quad$ NAO NPO SAO SPO

Figure 2: Ordination plot of epipelagic (left) and mesopelagic (right) communities based on OTU's composition based on canonical correspondence analysis (CCA). Percentages in parenthesis are the amount of variation constrained, in titles represents the total in each analysis, and in the axis the correspondent value for each dimension. Arrows represent environmental quantitative explanatory variables with arrowheads indicating their direction of increase. Shapes represent sampling sites. Shape formats represent eco-regions, epi: epipelagic, Oxic_mes: oxic mesopelagic, OMZ: OMZ mesopelagic. IO: Indian Ocean, NAO: North Atlantic Ocean, NPO: North Pacific Ocean, SAO: South Atlantic Ocean, SPO: South Pacific Ocean 


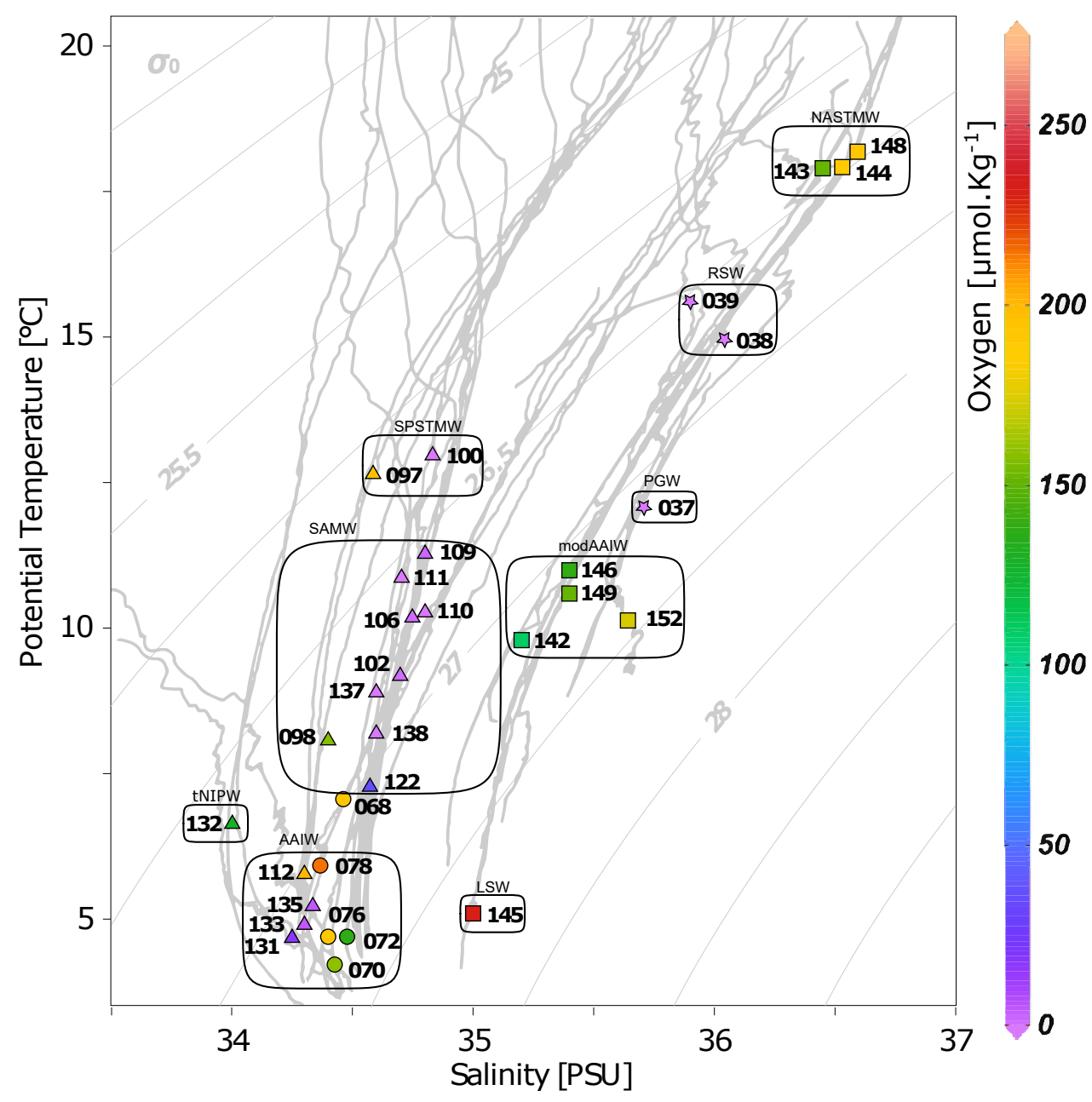

Figure 3: Temperature and salinity plot indicating water masses designation for all mesopelagic samples. Formats represent the different oceanic basins ( $\square$ - North Atlantic Ocean, $\bigcirc$ - South Atlantic Ocean, $\triangle$ - Pacific Ocean, $\star$ - Indian Ocean). Colours indicate the oxygen concentration at the sampling depth. LSW - Labrador Sea Water; AAIW - Antarctic Intermediate Water; tNPIW ? transitional North Pacific Intermediate Water; SAMW - Subantarctic Mode Water; SPSTMW - South Pacific Subtropical Mode Water; modAAIW - modified Antarctic Intermediate Water; PGW - Persian Gulf Water mass; RSW - Red Sea Water mass; NASTMW - North Atlantic Subtropical Mode Water. 
bioRxiv preprint doi: https://doi.org/10.1101/2021.02.26.433055; this version posted February 27, 2021. The copyright holder for this

preprint (which was not certified by peer review) is the author/funder. All rights reserved. No reuse allowed without permission.
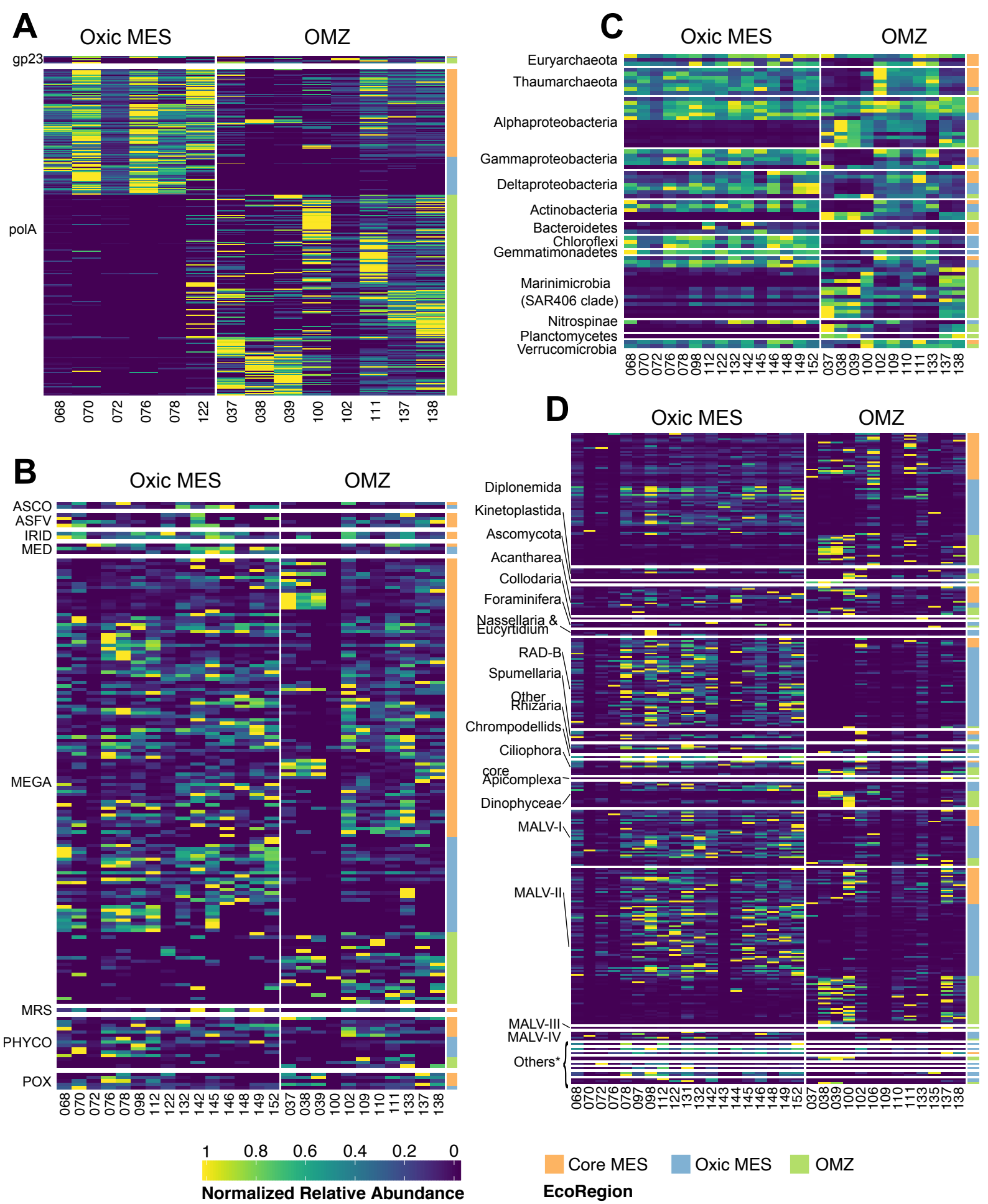

Core MES Oxic MES $\quad \mathrm{OMZ}$
EcoRegion

Figure 4: Relative abundance of OTUs assigned to Mesopelagic Eco-regions. A) Phages, B) Giruses, C) Prokaryotes and D) Eukaryotes 
A

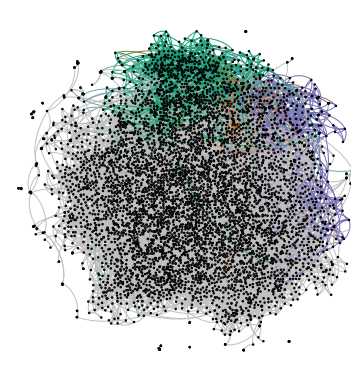

B

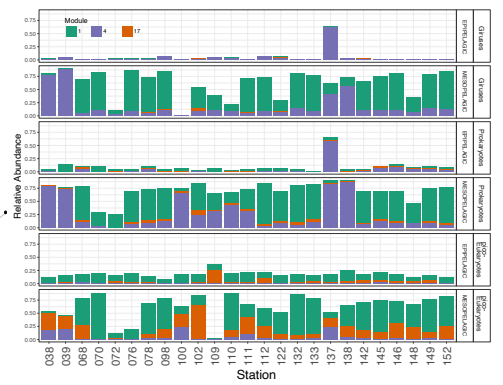

C

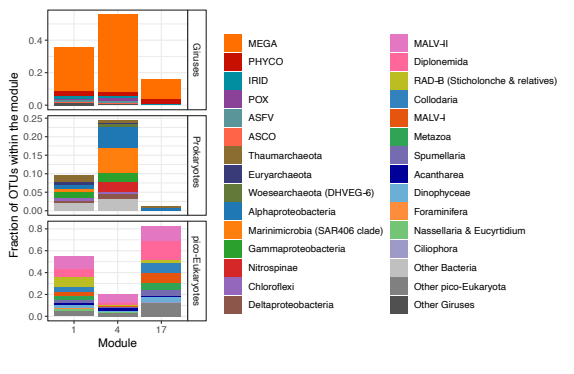

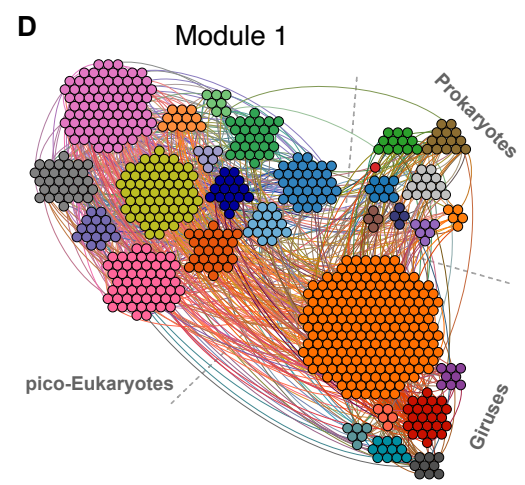
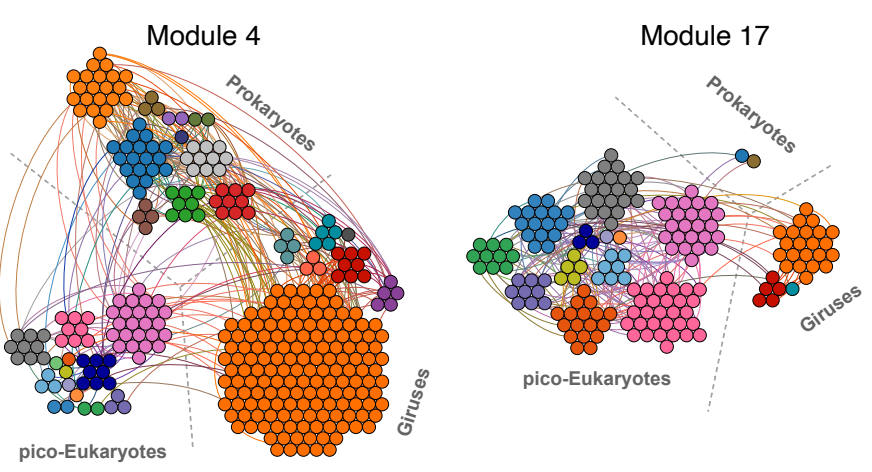

Figure 5: Co-Ocurrence Network in Epipelagic and Mesopelagic communities. A) Total Network, with connected modules for OMZ (purple and orange) and MES (green) highlighted. B) Relative taxa abundance in each Module in each station and depth. C) Relative number of OTUs classified in taxonomic groups. D) Network representation of modules 
bioRxiv preprint doi: https://doi.org/10.1101/2021.02.26.433055; this version posted February 27, 2021. The copyright holder for this

preprint (which was not certified by peer review) is the author/funder. All rights reserved. No reuse allowed without permission.

\section{${ }_{612}$ Tables}




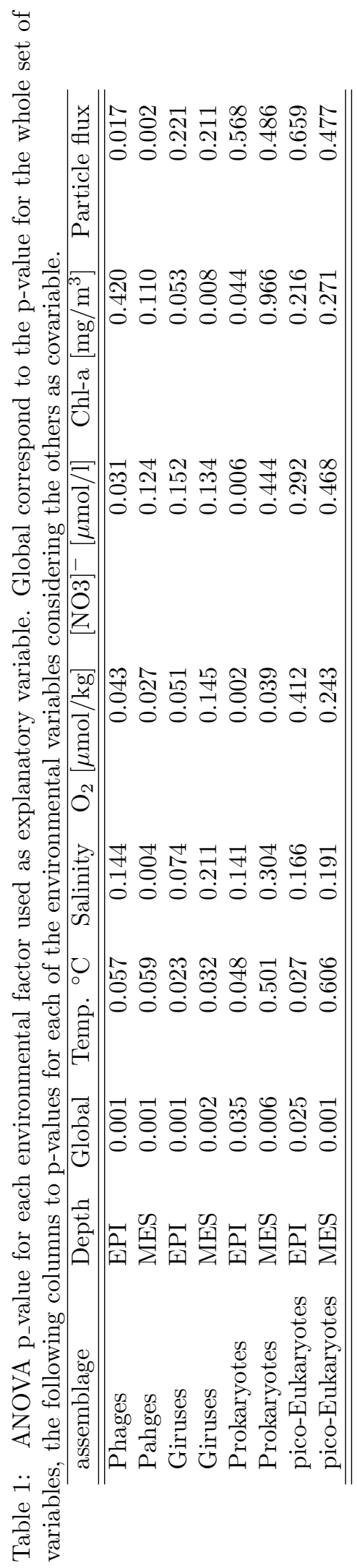


Table 2: Proportion of the variation in community composition that explained by water masses using the Permutation multivariated analysis of variance (PERMANOVA)

\begin{tabular}{lrrrrrr}
\hline assemblage & Df & Sum Of Squares & Mean Squares & F. Model & $\mathrm{R}^{2}$ & $\operatorname{Pr}($ ¿F $)$ \\
\hline \hline Phages & 4 & 1.87 & 0.47 & 2.32 & 0.51 & 0.002 \\
Giruses & 8 & 3.19 & 0.40 & 1.81 & 0.46 & 0.001 \\
Prokaryotes & 8 & 1.30 & 0.16 & 3.29 & 0.60 & 0.001 \\
pico-Eukaryotes & 8 & 2.60 & 0.32 & 1.62 & 0.36 & 0.001 \\
\hline \hline
\end{tabular}

Table 3: Network topological features derived from global analysis including giruses, prokaryotes and picoeukaryotes samples in epipelagic and mesopelagic depths

\begin{tabular}{lrrrr}
\hline Name & Global & Mod 1 & Mod 4 & Mod 17 \\
\hline \hline Nodes & 6154 & 731 & 323 & 175 \\
Positive Edges & 12193 & 1236 & 480 & 223 \\
Negative Edges & 742 & 70 & 49 & 9 \\
Avg. degree & 4.20 & 3.57 & 3.28 & 2.65 \\
Clustering & 0.03 & 0.03 & 0.09 & 0.05 \\
Density & 0.00 & 0.00 & 0.01 & 0.02 \\
Average.path.length & 7.28 & 6.01 & 6.27 & 6.30 \\
Betweenness & 0.01 & 0.05 & 0.10 & 0.22 \\
Degree Centralization & 0.00 & 0.01 & 0.02 & 0.04 \\
Modularity & 0.47 & 0.60 & 0.67 & 0.66 \\
\hline \hline
\end{tabular}




\section{${ }_{613}$ Supplementary Figures:}
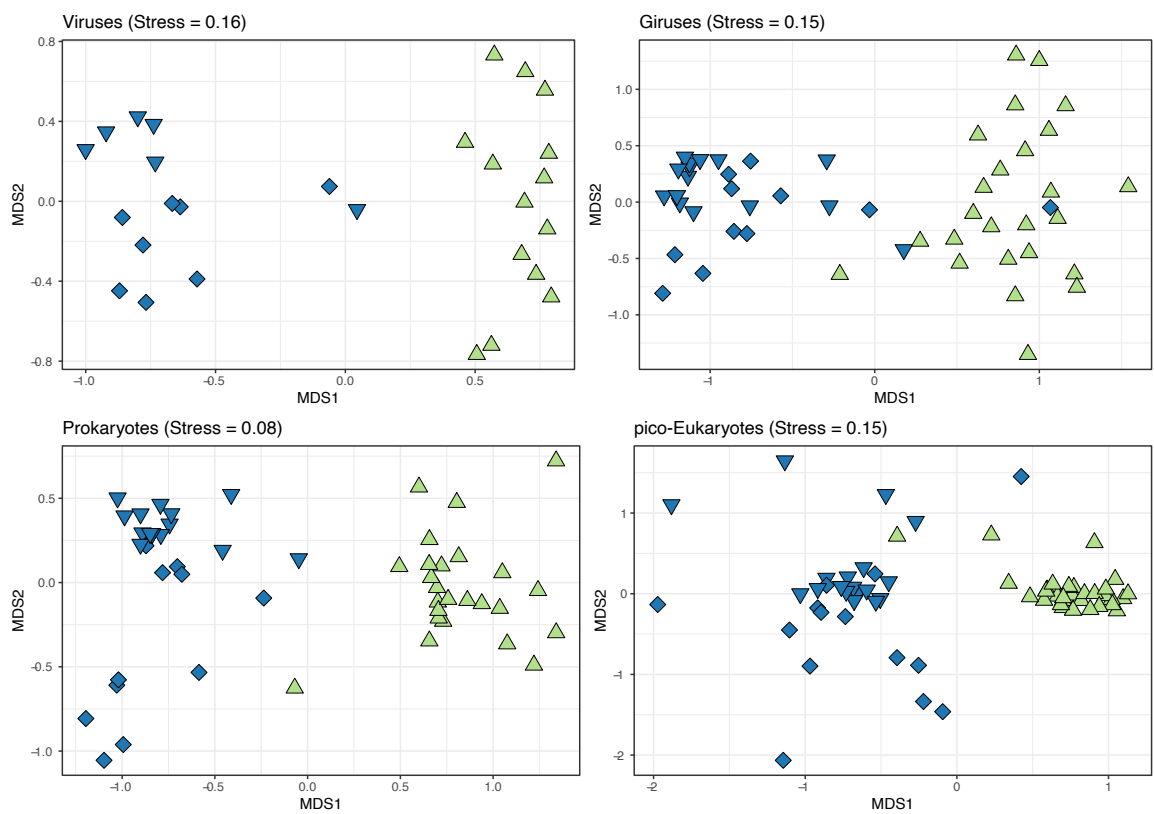

Supplementary Figure 1: Non-metric multidimensional scaling (NMDS) showing epipelagic and mesopelagic communities stratification for each organism group 
bioRxiv preprint doi: https://doi.org/10.1101/2021.02.26.433055; this version posted February 27, 2021. The copyright holder for this preprint (which was not certified by peer review) is the author/funder. All rights reserved. No reuse allowed without permission.
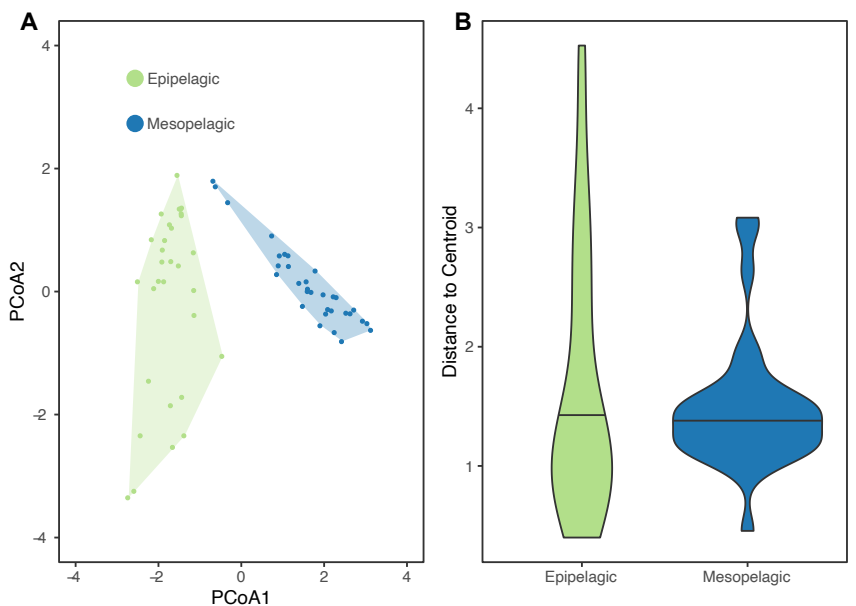

Supplementary Figure 2: Epipelagic and mesopelagic group dispersion based on physical-chemical oceanic properties (Euclidian method). A) First two axes of PCoA. B) Dispersion of distances from samples to centroids. 


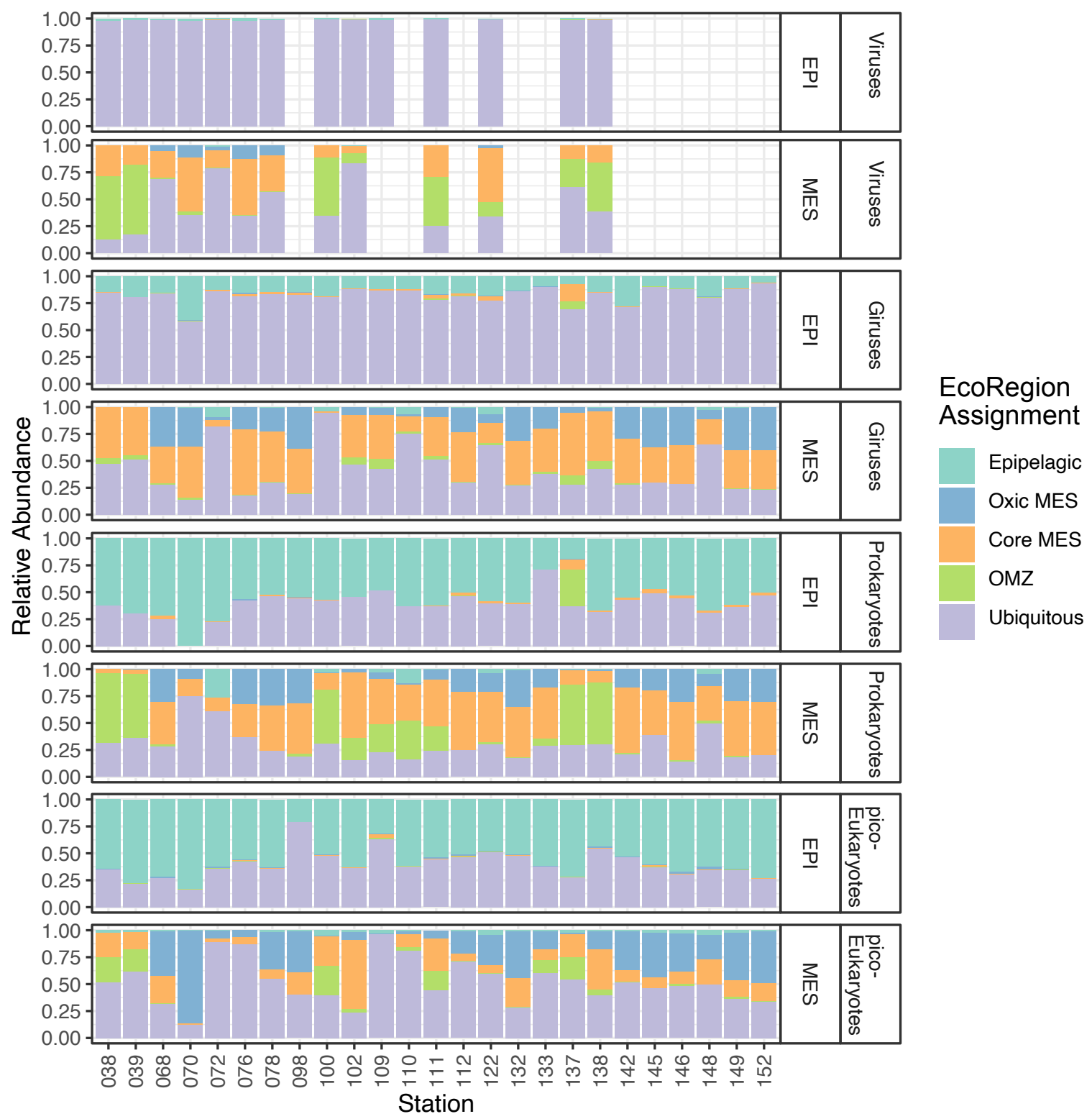

Supplementary Figure 3: Relative abundance of OTUs classified into different eco-regions in to ocean layers 


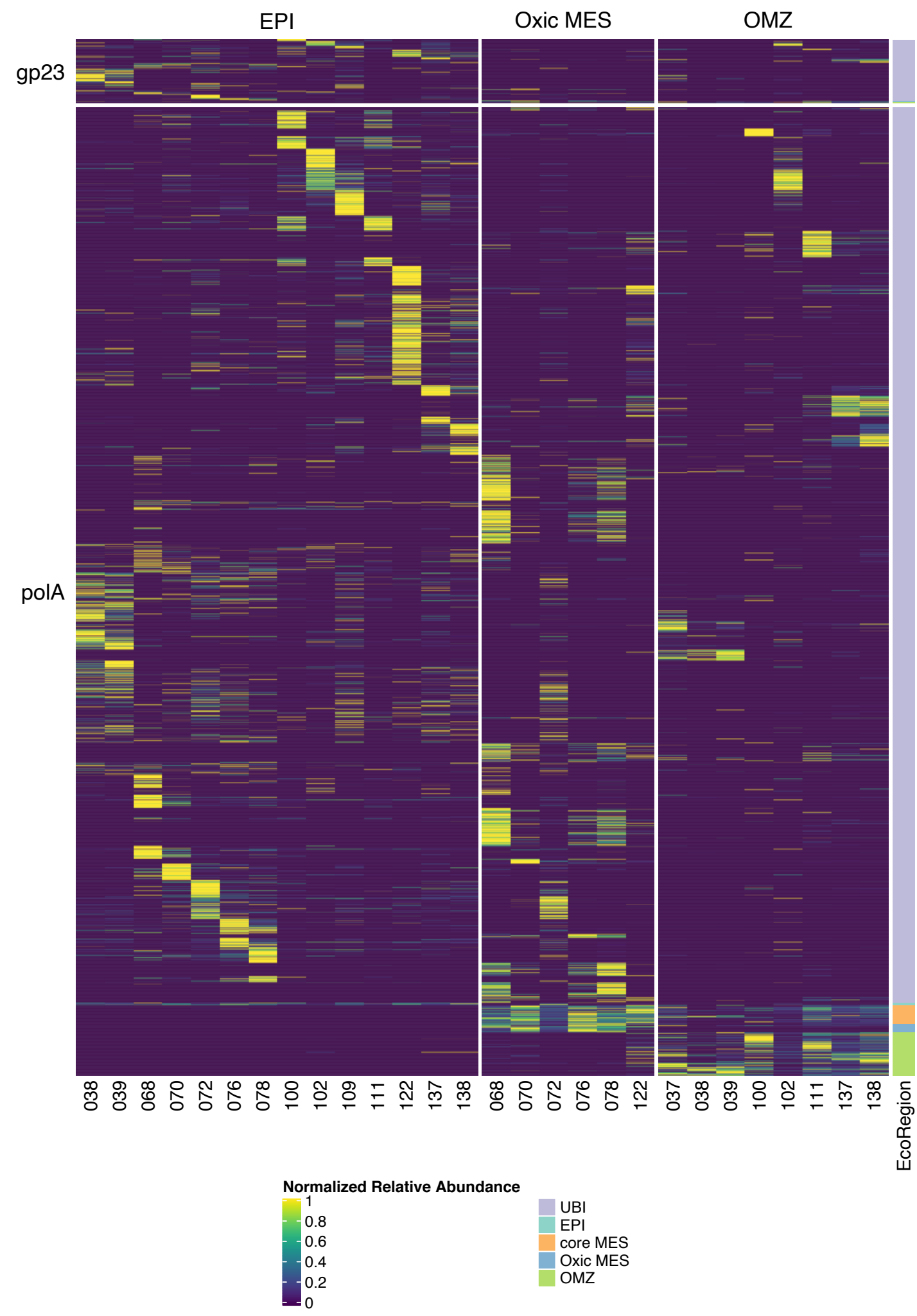

Supplementary Figure 4: Normalized Relative abundance of Phages and their preferred eco-region 


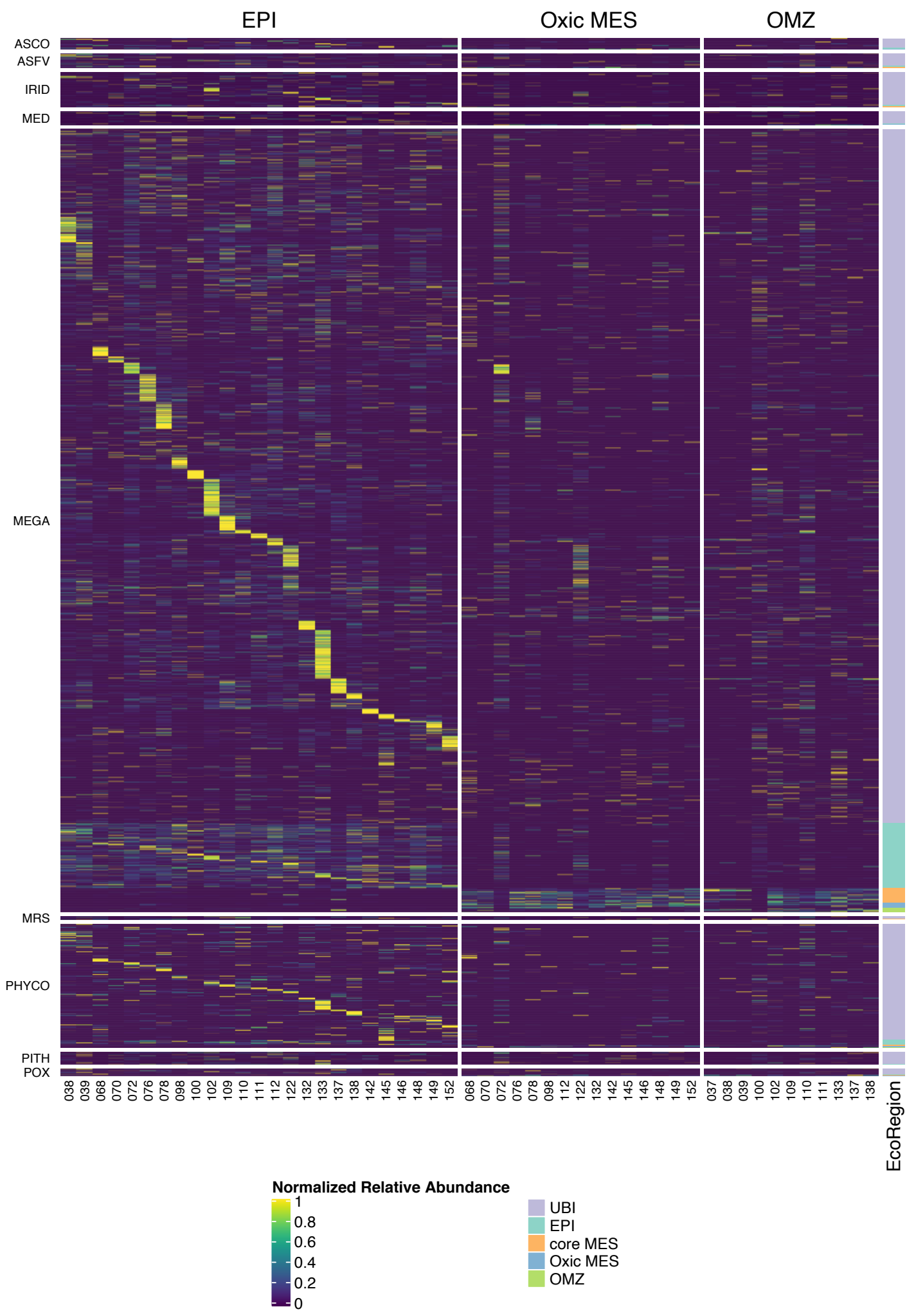

Supplementary Figure 5: Normalized Relative abundance of giruses and their preferred eco-region 


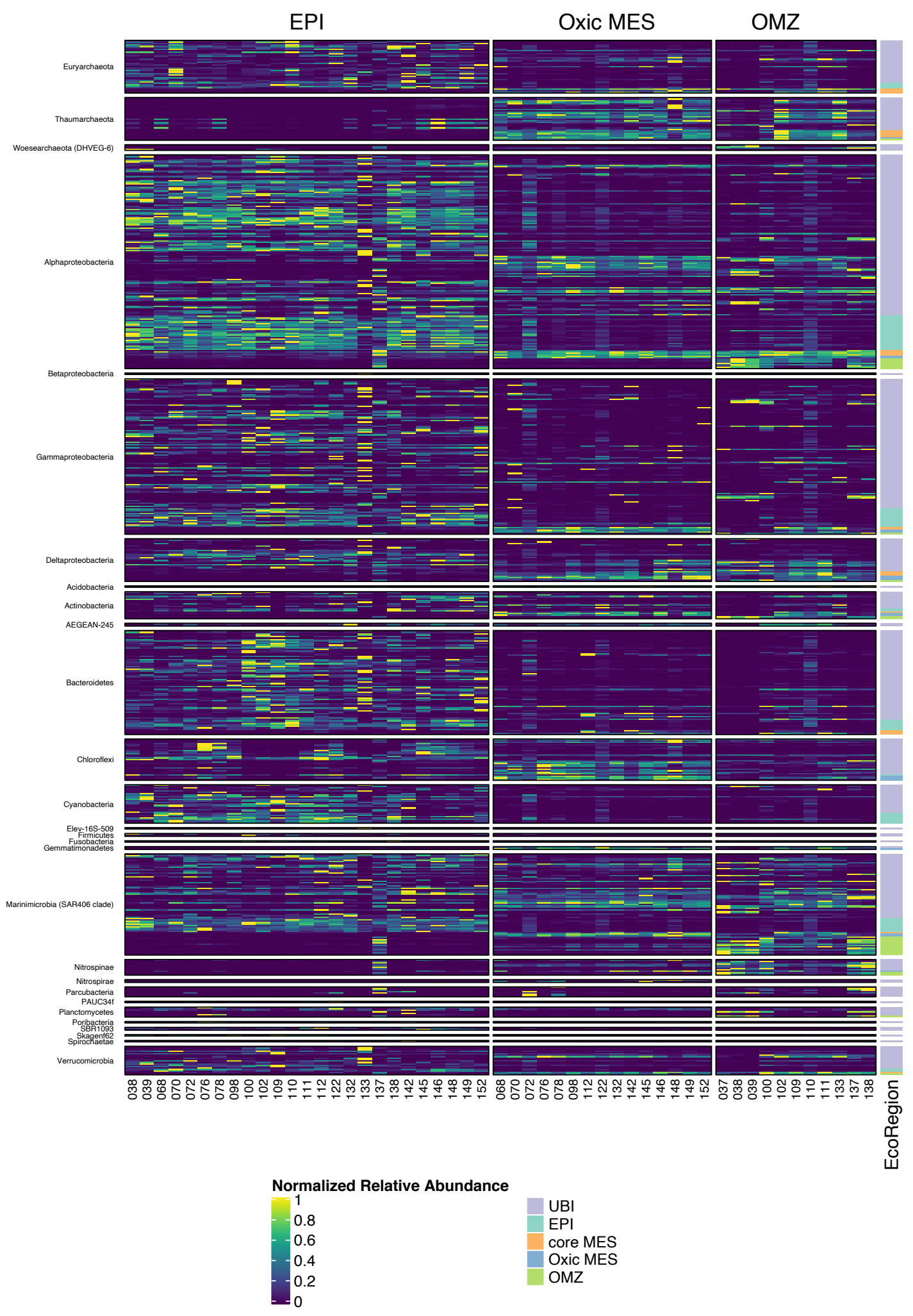

Supplementary Figure 6: Normalized Relative abundance of Prokaryotes and their preferred eco-region 

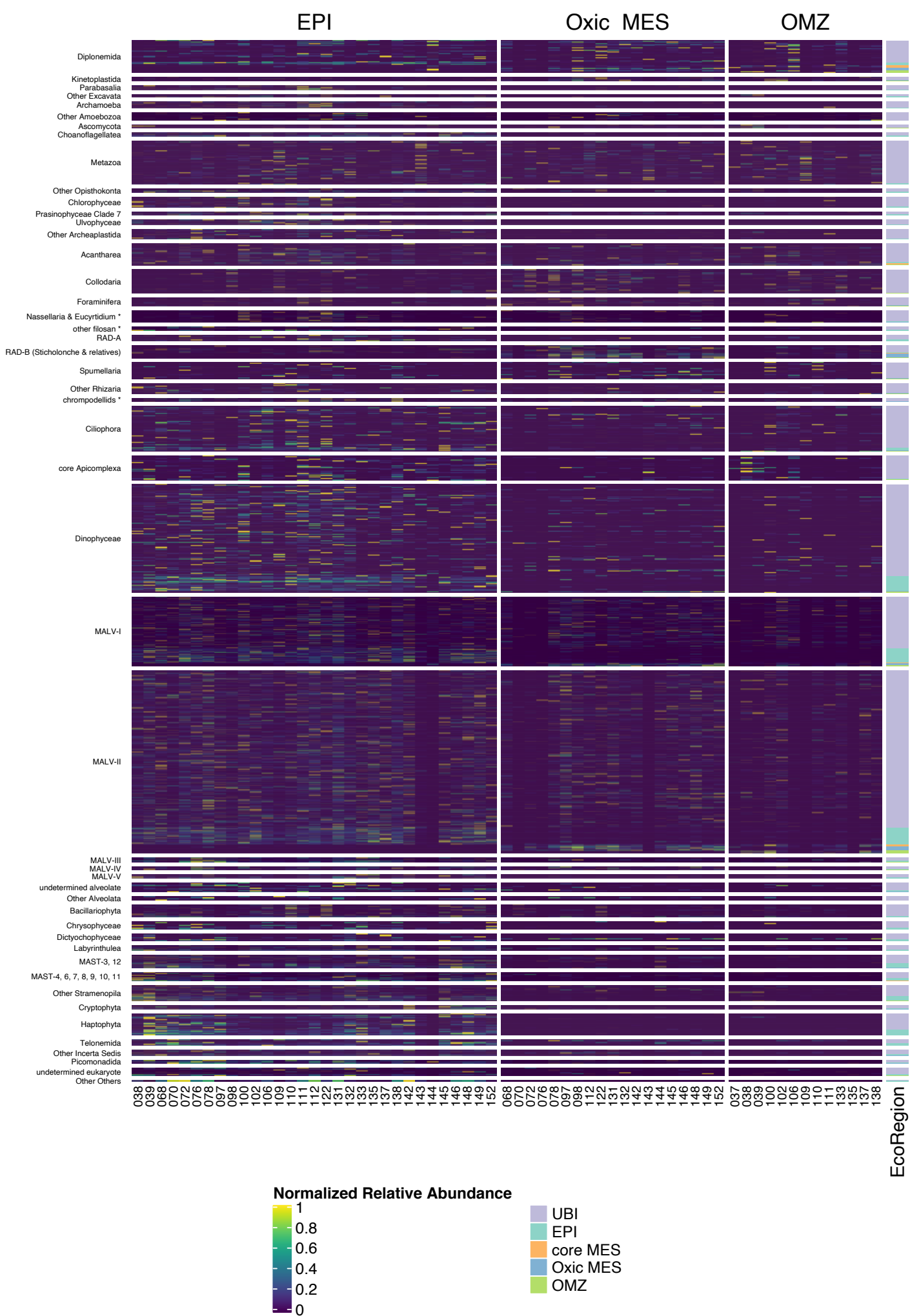

Supplementary Figure 7: Normalized Relative abundance of pico-Eukaryotes and their preferred eco-region 


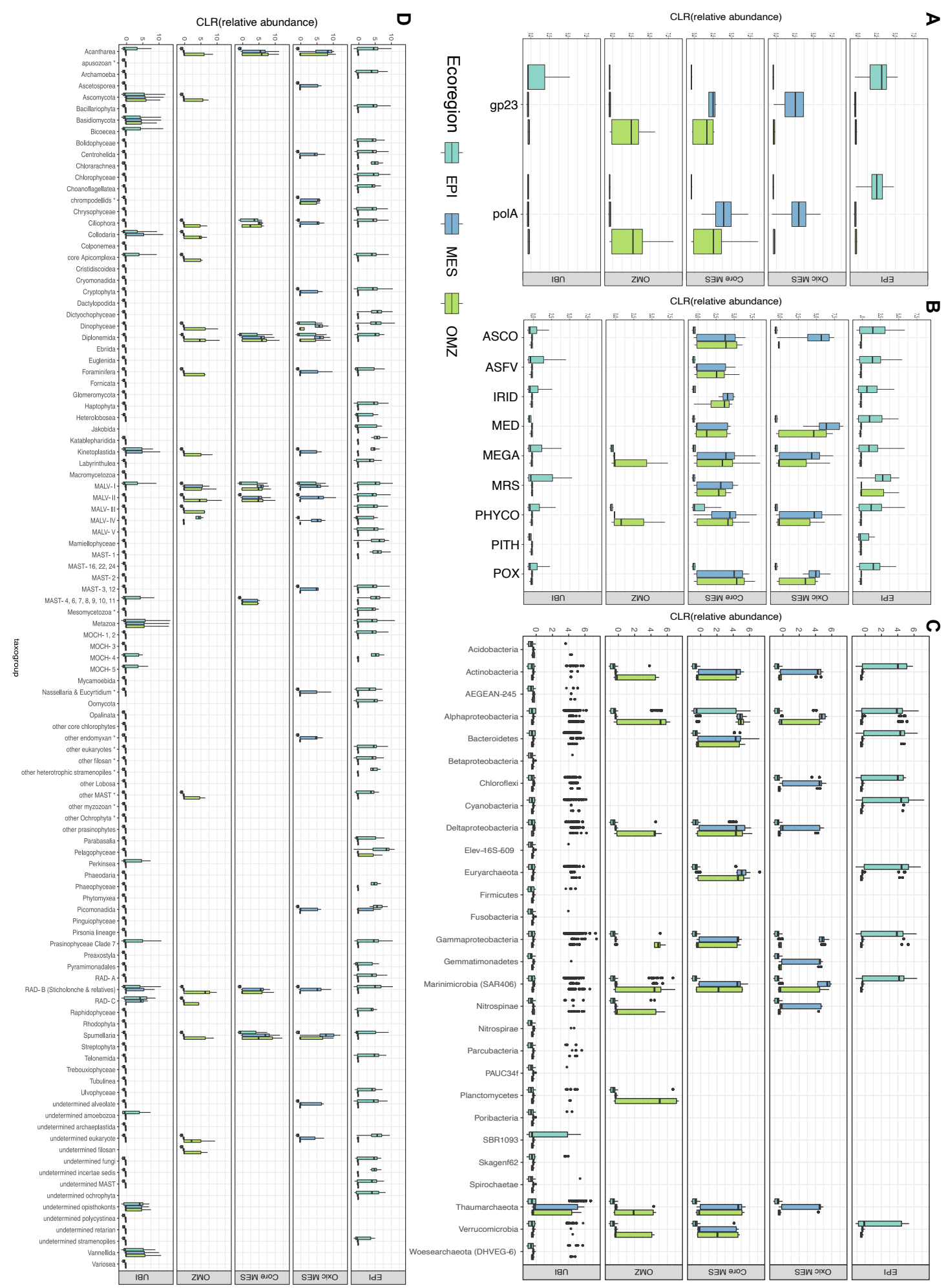

Supplementary Figure 8: Relative abundances of OTUs from taxonomic groups for epipelagic and mesopelagic (Oxic MES and OMZ) samples enriched in each eco-region (UBI: ubiquitous, EPI: epipelagic, Core MES: core mesopelagic, Oxic MES: oxic mesopelagic, OMZ: oxygen minimum zone. A) Phages B) Giruses C) Prokaryotes D) pico-Eukaryotes 